\title{
5. Competition policy in the electricity industry
}

\section{Guido Cervigni and Dmitri Perekhodtsev}

\subsection{INTRODUCTION}

Market power is a company's ability to profitably raise and maintain prices above the level that would prevail under competition. Market power is a primary concern in wholesale electricity markets for two broad reasons. The first is that electricity is a primary commodity purchased by every household and business, and its price is extremely important for the economy. The second is that the unique technical and economic characteristics of electricity make wholesale electricity markets particularly vulnerable to the exercise of market power. These characteristics are little or no demand responses to price changes, the fact that electricity is not storable, and tight transmission capacity constraints that reduce the scope for competition among generators connected in different locations. As a result, even small generators may have the interest and ability to induce dramatic price increases under certain conditions. The problem is exacerbated by the highly concentrated industries that have resulted in most countries from the liberalisation of electricity generation.

For these reasons, in some countries market power in the wholesale electricity market is addressed by regulatory statutes, the primary goal of which is to avoid excessive prices. In the US, for example, the Federal Power Act 1935 places a statutory obligation on the federal energy regulator to ensure that wholesale electricity prices are 'just and reasonable'. In Europe, charging excessive prices is an abuse of market power in breach of competition law, ${ }^{1}$ although historically the prohibition on charging excessive prices has proved hard to enforce. Recent policy developments confirm the difficulty for the European authorities in addressing marketpower issues in wholesale electricity markets in the current legal framework. For example, in June 2012 the Austrian government submitted a new cartel law to parliament, which turns around the burden of proof in cases of abusive high prices in the energy sector only. Under the new law, electricity and gas companies will have to justify their prices if they are 
higher than in comparable markets. ${ }^{2}$ In the UK, certain pricing policies by generators in case of congestion - which do not violate the competition rules - have been banned through an ad hoc licence condition.

In the electricity generation market, more frequently than in others, the regulatory authorities implement structural or quasi-structural measures in order to mitigate market power, or enforce specific ex ante restrictions on companies' behaviour, such as price caps, bidding restrictions or mandated cost-based offers. These measures complement the deterrence of harmful conduct through the prospect of ex post investigations and fines for breach of competition laws.

The standard competition policy toolbox needs to be tailored to the specific technical features of electricity supply. In particular, the non-storability of electricity, demand price inflexibility and network constraints make application of the standard methodology to determine the market boundaries - the hypothetical monopolist test - less than straightforward. Furthermore, as the competitive interaction among generators takes place in auction-based markets, the usual concentration measures based on market shares may be poor indicators of market power in electricity generation.

In Sections 5.2 and 5.3 we discuss the methodology for assessing competition in wholesale electricity markets based on market structure (5.2) and the generator's market behaviour (5.3). In Section 5.4 we analyse the main market-power mitigation measures implemented in wholesale electricity markets. Finally, in Section 5.3 we present a selection of competition policy cases.

\subsection{MARKET POWER ASSESSMENT BASED ON MARKET STRUCTURE}

The assessment of competitive conditions and market power is a key element of antitrust and merger control cases. Certain business practices are regarded as abusive if implemented by a firm enjoying considerable market power, or in a dominant position, while being allowed for non-dominant firms. A merger between firms operating in the same market may not receive approval from the competition authorities, or be approved subject to conditions, if it is likely to restrict competition.

A firm is said to have market power if its customers and competitors exercise few constraints on its actions, so that the firm has the ability and the incentive to raise and maintain the price above the level that would prevail under competition. Figure 5.1 illustrates the concept of market power. Both panels of the figure show the firm's competitive supply: in 

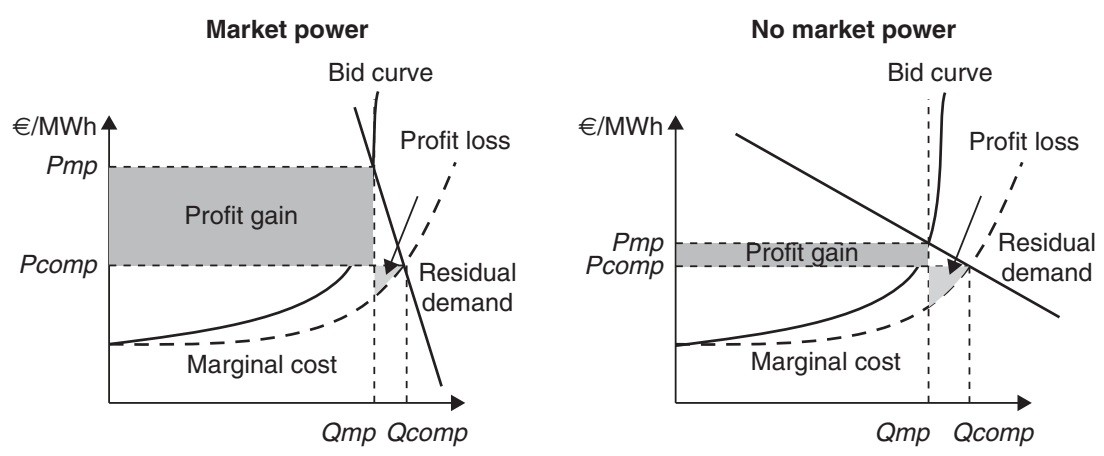

Figure 5.1 Ability and incentives to exercise market power

a competitive environment the firm will increase sales until the cost of producing an additional unit equals the price. In other words, the firm's competitive supply coincides with the firm's marginal cost function.

The figure also shows the residual demand faced by the firm. For each price level, the residual demand represents the market demand net of the volumes supplied by the firm's competitors. The residual demand summarises the pressure exercised on the firm by the supply of competing generators and by the reaction of customer demand to price changes.

In the figure we assume for simplicity's sake that the entire supply of the firm is submitted in the spot market in the form of a bid curve. The firm's bid curve and residual demand cross at the market-clearing price. Setting the price above the competitive level has two contrasting effects on the firm's profits: on the one hand a profit loss because of the decrease in the volumes sold, and on the other a profit gain because of the increase in the margin obtained on sales at the higher price.

The left panel of the figure illustrates a situation where the firm has market power. A price increase above the competitive level brings about a net increase in the firm's profit. The additional margin obtained on the volumes sold at the higher price outweighs the negative impact of the reduction in sales. ${ }^{3}$ The right panel illustrates a situation without market power. The same bid curve induces a small price increase, and the profit gain on the volumes sold is insufficient to outweigh the profit loss caused by the reduced sales.

Different slopes of the residual demand, which determine whether or not the firm has market power, represent different strengths of the competitive constraints of competitors and the price elasticity of demand.

Below we discuss the nature of competitive constraints in wholesale electricity markets in greater detail. We then present two approaches to 
assessing the degree of competition in wholesale electricity markets: the traditional approach applied to a wide variety of markets in competition policy and an alternative approach that directly assesses competitive constraints.

\subsubsection{Competitive Constraints in Wholesale Electricity Markets}

The market power of an electricity generator can be mitigated by the reaction of the consumers and of competing generators to a price increase. We discuss these in turn in the following subsections.

\section{Electricity demand elasticity}

Electricity demand is typically considered very inelastic. This is partly because electricity is the only available energy source for most uses, and can only be substituted by other fuels such as natural gas or fuel oil in a limited number of cases. However, such substitution involves replacing appliances and should be regarded as long term rather than a possible demand response to a price change in the short run. Therefore it is commonly considered that short-run demand-side substitution provides few constraints on the market behaviour of firms operating in the wholesale electricity markets.

As discussed in Chapter 2, much of the electricity produced and consumed is traded on forward markets, with various time horizons. Transactions are executed on exchanges, trading platforms and bilaterally. The question often arises as to whether electricity volumes sold in different trading venues and with different forward horizons are substitutes. When wholesale markets are liquid, one would expect market participants to be able to arbitrage freely across the different products and trading venues. A sustained increase in prices on the spot market would induce a shift of demand away from spot to forward products, which would also increase forward prices. A price increase for products sold on a power exchange would lead to a shift in demand towards bilateral trades, which would result in an equal price increase. On this basis it is commonly considered that all transactions involving the production and consumption of electricity at a certain time are good substitutes and therefore belong to the same market. ${ }^{4}$

However, real-time and re-dispatch transactions are, at least in the European context, typically not considered to be part of the wholesale electricity market. This is the consequence of several features of the design of the European electricity markets, including the following:

- small generators and all but very large consumers are generally not allowed to participate in the re-dispatch and real-time markets; and 
- the imbalance pricing system in most countries makes voluntary imbalances (a way to trade on the real-time market) unprofitable, irrespective of the actual cost (or cost reduction) for the system operator.

\section{Competition among generators}

If a firm operating in the wholesale electricity market increases its offer prices, competing generators will get to produce more. In wholesale electricity markets this displacement takes place immediately, thanks to power exchanges that clear bids and offers according to their price merit order.

The extent of competitive constraints may vary hour by hour depending on the demand level, the corresponding set of competing generators and fuel prices. In Figure 5.2 we illustrate how demand level impacts on the competitive constraint faced by a generator. We consider the competitive situation in off-peak and peak hours. On the supply side, we assume that only two technologies are available, with materially different variable cost ( $V C$ in the figure): base-load technology with low variable cost, and peak technology with a high variable cost.

We can now assess the market power of a firm controlling a large portion of the base-load capacity but none of the peak capacity. In this case the competitive pressure faced by the firm is very different in peak and off-peak hours. In off-peak hours the firm enjoys significant market power. It finds it profitable to set a price just below VC Peak, as shown in the figure, well above the competitive level VC Base-load. However, in peak hours, when the market price is set by the variable cost of peak

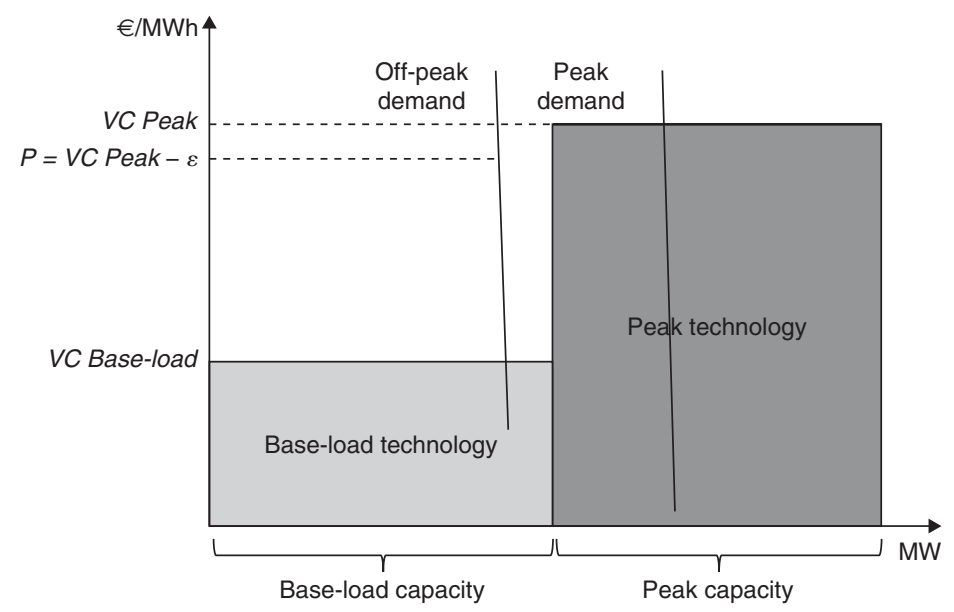

Figure 5.2 Competition for different demand levels 


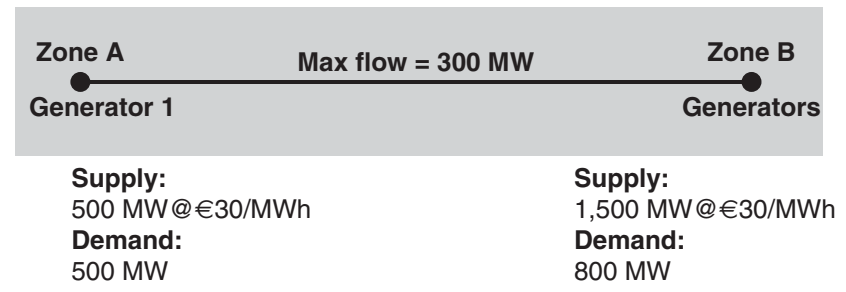

Figure 5.3 Market power and transmission constraints

technology, the competitors controlling peak capacity make it unprofitable for the firm to set a price above the competitive level VC Peak, because doing so would require a large reduction in the volumes sold.

Note incidentally that, since electricity is non-storable on a massive scale, it is impossible for electricity produced at one time to replace electricity produced at another time, or in other words for the generation capacity in service at one time to compete against the generation capacity in service at another time. Furthermore, the cross-elasticity of demand at different times appears to be very limited: very few consumers would postpone electricity consumption in the event of a four-hour price increase, for example. As a consequence, the decision to consider large sets of hours as part of the same market is based not on supply- or demand-side substitutability across hours, but on the assessment that very similar competitive conditions hold in all hours. ${ }^{5}$

The displacement of a generator increasing the offer price by generators connected to the transmission network at different locations can be limited by the presence of transmission constraints. Consider the example of two areas, illustrated in Figure 5.3. In this figure Generator 1 with a capacity of $500 \mathrm{MW}$ and demand of $500 \mathrm{MW}$ is located in zone A and generators with a combined capacity of 1,500 MW and demand of $800 \mathrm{MW}$ are located in zone B. We also assume that the cost of all the generators is identical.

If transmission capacity connecting the two zones were unlimited, the generators located in zone B could exert strong competitive pressure on Generator 1. A slight increase in the offer price of Generator 1 would place its capacity out of merit, and generators from zone B would supply the demand in both zones $\mathrm{A}$ and $\mathrm{B}$.

However, a constraint of $300 \mathrm{MW}$ on transmission capacity between the zones could dramatically reduce the competitive pressure from generators in zone B on Generator 1. The available transmission capacity would only allow the generators from zone B to meet $300 \mathrm{MW}$ of the demand in zone A, and the remaining $200 \mathrm{MW}$ of demand would have to be met by Generator 1, allowing it to set a higher offer price in its zone. ${ }^{6}$ 


\subsubsection{The Standard Approach to Market-power Assessment}

In competition policy, market-power assessment is generally carried out in two steps. ${ }^{7}$ First, the boundaries of the relevant market or markets are identified (market definition). Then the degree of competition is assessed through concentration indices based on the market shares of the firms belonging to the relevant market identified in the first step (competitive assessment). Below we discuss these steps of the standard approach and its weaknesses when applied to wholesale electricity markets.

\section{Market definition analysis}

According to the European Commission:

Market definition is a tool to identify and define the boundaries of competition between firms. ... The objective of defining a market in both its product and geographic dimension is to identify those actual competitors of the undertakings involved that are capable of constraining those undertakings' behaviour and of preventing them from behaving independently of effective competitive pressure. ${ }^{8}$

The standard conceptual framework for market definition is the hypothetical monopolist test, or SSNIP test (small but significant nontransitory increase of price). The test starts with identification of the smallest conceivable candidate market, that is, the smallest set of products and locations that are believed to be highly substitutable and therefore to belong to the same market.

The second step of the test consists of assessing the competitive constraints that the products and firms external to the candidate market could exercise on the products and firms included in the candidate market. This is done by assessing whether a hypothetical monopolist in the candidate market would find it profitable to implement a small (typically 5-10 per cent) price increase for a relatively long period (such as one or two years). Such a price increase is less profitable the more it results in:

- customers replacing the products supplied by the hypothetical monopolist with products not included in the candidate market demand-side substitution - or

- other firms switching their production facilities to produce the products included in the candidate market - supply-side substitution.

For example, in the retail car market the initial candidate market could include all makes of city cars sold in a certain city. The profitability of 
the price increase by a hypothetical monopolist in this candidate market would depend on:

- The price elasticity of the demand for city cars. Following the price increase the demand for city cars would reduce as the customers substitute it with other products. For example, an increase in the price of city cars might lead consumers to buy fewer city cars and more medium-sized cars. Alternatively, consumers could travel to neighbouring cities not included in the candidate market to buy city cars. These are instances of demand-side substitution.

- The behaviour of retailers operating at other locations or retailers of different types of cars operating in the candidate market area. The former could find it profitable to respond to the price increase by opening branches selling small cars in the candidate market. The latter could expand their offering of city cars in the candidate market at little cost. These are two examples of supply-side substitution.

If demand- and/or supply-side substitutions are major enough to make the price increase unprofitable for the hypothetical monopolist, this indicates that the products included in the candidate market are subject to competition from some of the products excluded from the candidate market. In this case the profitability of a price increase by a hypothetical monopolist is tested for a larger candidate market, including the product and/or location that are the best substitutes for those making up the first candidate market. The candidate market is enlarged and the test is repeated until the price increase turns out to be profitable. The set of products and geographical locations found in this way satisfy the requisites that define a market: they exercise significant competitive pressure one on the other, while facing limited competitive pressure from those external to the set. In the car example, the candidate market might have to be expanded to include all the small and medium-sized cars sold in the entire country.

The application of SSNIP logic to assess the boundaries of wholesale electricity markets along the product, geographical and temporal dimensions reflects the nature of the competitive constraints in the market discussed above. When markets are sufficiently liquid, a high degree of substitution between spot and forward electricity transactions executed bilaterally and on exchanges is to be expected. ${ }^{9}$ For this reason such transactions are often considered as belonging to the same market, and the competitive assessment is then carried out as if all electricity produced and consumed were exchanged on a spot basis, under the assumption that arbitrage between the spot and the forward markets takes place. ${ }^{10}$ 
However, in the European context, real-time and re-dispatch transactions are often considered a separate product market. ${ }^{11}$

Second, in electricity markets competitive conditions may vary greatly between different hours. This is because different demand levels typically correspond to different sets of potentially competing generators. In addition, the generation merit order may change as a result of changes in prices of fuels and $\mathrm{CO}_{2}$ permits. For this reason several distinct relevant markets may be identified at different levels of demand. The US Federal Energy Regulatory Commission (FERC) implements various tests in order to assess the market power of generators applying to be exempted from price regulation. ${ }^{12}$ One of these is the delivered price test, which identifies 'potential suppliers based on market prices, input costs, and transmission availability'. ${ }^{13}$ FERC considers 10 separate periods of the year, potentially featuring different structural conditions. ${ }^{14}$ For each period, FERC determines a representative market price and identifies the relevant market as the set of generators with variable costs lower than 105 per cent of the reference variable cost. Competitive assessment is then carried out for that market. ${ }^{15}$ The Brattle Group has investigated the wholesale electricity market definition in the Netherlands in the context of merger control. ${ }^{16} \mathrm{On}$ the basis of the observed price differentials they recommend considering three separate markets: off-peak, peak and super-peak hours. ${ }^{17}$

Finally, transmission constraints may determine boundaries to the relevant geographical markets for wholesale electricity. For instance, when transmission constraints are binding in the direction of a large load centre, this centre may become a separate relevant market, or a load pocket, because generators located outside of the load pocket may not exert any competitive pressure on the generators within the pocket. The geographical dimension of the relevant market may vary in different sets of hours because the level of demand has a major impact on network congestion and the resulting geographical boundaries of the wholesale electricity market. $^{18}$

\section{Competitive assessment}

Once the relevant market has been identified, the standard approach assesses market power indirectly, through indices based on the market shares of firms operating in the relevant market. Measuring market power through concentration indices has an intuitive appeal. Other things being equal, one would expect a monopolist with a 100 per cent share to have the highest possible market power and a very small firm to be unable to exercise market power. Competition authorities rely on market-share thresholds to judge market power. A firm with market share in excess of 70 per cent is presumed to be dominant. A share between 50 and 70 per cent 
raises a weaker presumption of dominance. A market share below 40 per cent is commonly regarded as unable to support a finding of dominance. ${ }^{19}$

A widely used index of market concentration based on market shares is the Hirschman-Herfindahl Index (HHI). The HHI is calculated as the sum of squares of the market shares $s$ of the suppliers in the market. ${ }^{20} \mathrm{In}$ European case law, HHI levels above 2,000 are generally considered to indicate a concentrated market, whereas HHI levels below 1,000 indicate a non-concentrated market. In the US electricity market, FERC considers that a generator does not raise market-power concerns provided that the HHI is below 2,500 and the generator's market share is less than 20 per cent (in production capacity), or the generator's market share is above 20 per cent and the HHI less than 1,000.

The wide use of market share and especially the HHI to assess competition in the relevant market is supported by the theoretical models most commonly used to describe the strategic interaction between imperfectly competing firms in the market. For example the Cournot model, ${ }^{21}$ the workhorse of competition analysis, establishes the following relationship between the HHI and the price mark-up over the marginal cost resulting from the imperfect competition in this market:

$$
\frac{p-c}{p}=\frac{H H I}{\varepsilon},
$$

where $\varepsilon$ is the elasticity of demand in the relevant market. As the equation shows, the price-cost mark-up - the measure of market power - is directly related to the HHI if the interaction between the firms in the market is well described by the Cournot model.

\section{Issues with application of the standard approach to wholesale electricity markets}

The standard approach to market-power assessment is widely used and applied to a variety of markets because of its simplicity. Calculation of market share within an identified relevant market is straightforward and requires only very basic data. Quantitative implementation of the SSNIP test may still be quite a data-intensive and complex exercise, but in practice it is often performed approximately using high-level qualitative information.

Nevertheless, application of the SSNIP test to wholesale electricity markets presents specific issues related to the unique technical features of electricity. First, the assumption underlying the reference to a 5-10 per cent price increase in the SSNIP test is that if the 5-10 per cent price increase turns out to be unprofitable for the hypothetical monopolist, a 
larger price increase will be all the more unprofitable as it will cause more intense demand- and supply-side substitution. This may not happen on the wholesale electricity market. The relationship between the price increase and the hypothetical monopolist's profit may not be monotonic, because once the competitors' capacity is fully utilised, both demand and the competitors' supply are completely price inelastic in the short term.

Second, because of transmission constraints the boundaries between the different geographical markets may not be symmetrical. For example, consider a merger between some generators in area $\mathrm{A}$ in the basic two-area network shown in Figure 5.3. In order to identify the relevant market the SSNIP test would be run, starting with area A, to verify if the generators in B would provide an effective competitive constraint for the generators in A. We assume that the SSNIP test leads to the conclusion that the generators in A and in B belong to the same market. However, the SSNIP test that determines whether generators in $\mathrm{B}$ are an effective competitive constraint for those in A does not necessarily imply that generators in A are an effective competitive constraint for those in B. Depending on the demand and supply conditions in A and in $\mathrm{B}$, the same transmission capacity might be enough to discipline a hypothetical monopolist in A, but not in B. As a result, the market definition will be different depending on whether the first step of the SSNIP test uses area A or area B as a candidate market.

Third, as we discussed extensively in Chapter 4, in real, highly meshed transmission networks the relationships of complementarity and substitutability between production at different nodes may be complex and unstable. As a consequence, identifying the sets of generators to include in a candidate market within the context of the SSNIP test may be a daunting exercise. The problem is exacerbated by the possibility that the outcome of the SSNIP test could be path dependent. For example, it could be that, (i) by adding a certain portion of network $x$ to a starting candidate market, the SSNIP test concludes that a market has been found and the investigation stops; but (ii) the same conclusion would have been reached had a different portion $y$ of the network been added to the initial candidate market instead of portion $x$. In other words, the boundaries of the market that is ultimately identified through the SSNIP test depend on the order in which additional areas of the network are considered.

The specific features of the electricity market also impact on the methodology used to assess the level of competition. The use of the HHI to assess market power is justified by the Cournot model of oligopoly. This model predicts that the market price will be proportional to the HHI, and inversely proportional to the price elasticity of demand. However, the model fails to provide meaningful results when applied to electricity markets with nearly zero demand elasticity. ${ }^{22}$ 
Furthermore, trading in the spot wholesale markets takes place through auctions, and a substantial body of economic analysis focuses on the generators' optimal bidding strategy in that framework. ${ }^{23}$ These analyses suggest that the Cournot model is not suitable for describing the interaction between generators in the auctions and that type of market power. As a consequence, the relationship between market structure and market power, on which the assessment of market power through concentration indices is based, appears not to hold for wholesale electricity.

\subsubsection{Market-power Assessment through Structural Models}

A more theoretically rigorous approach to assessing market power in wholesale electricity markets is through an equilibrium market model. In this approach, a model is identified that is believed to accurately represent strategic interaction between the generators on the market. The model parameters are estimated based on the observed market variables. The departure of the observed market outcomes from those that would prevail under perfectly competitive conditions is then assessed on this basis. The model is also used to predict the prices that would result from a concentration in the industry. ${ }^{24}$

Equilibrium models are appealing for their theoretical basis, as they consider the offer strategy of each generator to be the maximum-profit response to other generators' offers. However, most such models find multiple results in terms of possible market equilibrium. This reduces the model's ability to predict the market outcome under market conditions different from those on which it has been estimated, as would happen if the model were used to assess the effect of a merger. In addition, market equilibrium models are typically based on a highly simplified representation of the generators' cost function, and neglect the links between offer strategies that come into play at different times. These drawbacks, along with the intrinsic complexity of the approach, limit the use of equilibrium models in regulatory and antitrust proceedings.

\subsubsection{Direct Methods to Assess Market Power and the Pivotality Approach}

Alternative approaches to assessing market power have been developed to overcome some of the standard methodology issues. For example, direct approaches may involve estimating the residual demand (illustrated in Figure 5.1, above) faced by a given firm each hour. In areas where bidding data are publicly available and the bids can be associated with specific generators, residual demand elasticity can be explicitly estimated 
from the bids of competitive generators. The residual demand is given by the market demand after subtracting the supply bids of all the other participants and the net import schedules. Analyses of the residual demand elasticity were performed in order to rule on market concentration in the electricity markets of California, New Zealand and Italy. ${ }^{25}$ However, the data required to directly estimate the residual demand are not always available. In such cases, a simplified analysis of residual demand can be performed, known as a 'pivotality analysis'.

\section{Measuring generators' pivotality}

Pivotality measures the ability of a particular generator, or group of generators, to set the market price when all other suppliers bid competitively. For example, in a market in which the total generating and import capacity is $10,000 \mathrm{MW}$ and the demand in a given hour is $8,000 \mathrm{MW}$, a generator controlling more than 2,000 MW capacity is indispensable, or pivotal, since demand cannot be met without using at least part of that generator's capacity. Given the extremely low elasticity of the demand for electricity, this operator is then able to command any price for its output, up to the value of lost load, or VoLL. Figure 5.4 illustrates the notion of pivotality.

In the figure we assume for simplicity's sake that all generators have the same variable cost and we assess the competitive position of Generator 1. Some of the capacity controlled by Generator 1 is necessary to meet load even if the capacity of all the other generators and the import capacity are fully used. Generator 1, then, is pivotal. Given that demand is inflexible

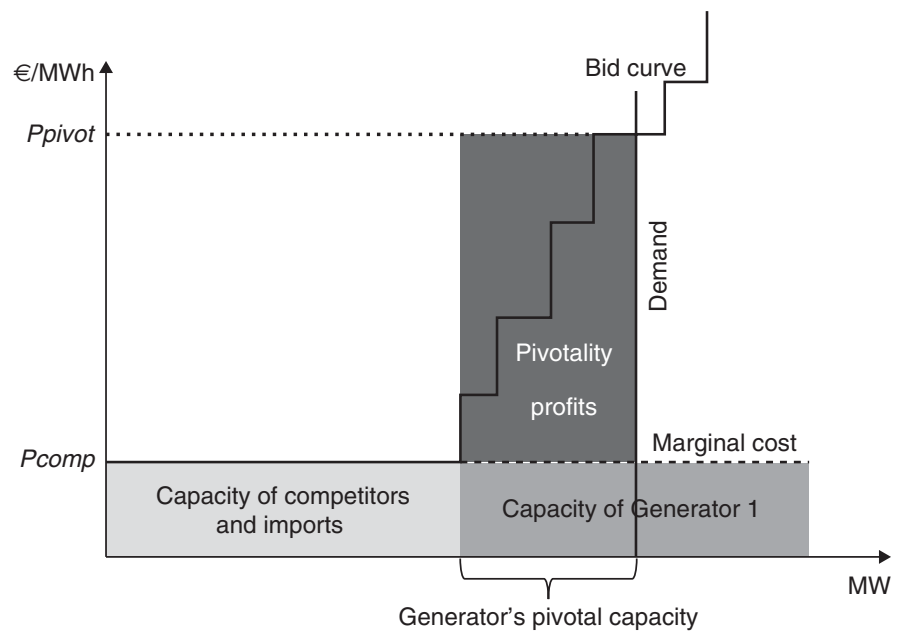

Figure 5.4 Generator's pivotality 
in the short run, Generator 1 has the ability to set the market price at an arbitrarily high level. ${ }^{26}$ The minimum capacity of a generator that needs to be scheduled to avoid an outage is its pivotal capacity.

Several indices of market power have been developed based on the concept of pivotality. ${ }^{27}$ They assess a generator's market power according to the number of hours in which the generator is pivotal over a long period such as a year, and/or on the generator's pivotal capacity.

The assessment of market power based on pivotality indices does not require an explicit preliminary assessment of the geographical boundaries of the market. The pivotality calculation takes into account the competitive pressure exercised by generators located outside the area for which the generator's market power is being assessed, by assuming that the entire transmission capacity can be used to import electricity.

We discuss below the limitations of the assessment of market power based on pivotality and possible adjustments to the simpler pivotality analysis.

\section{An extreme model of competitive interaction}

The pivotality indices reflect a very specific scheme of competitive interaction, in which market power is exercised only when the generator is necessary in order to satisfy demand. Specifically, pivotality measurements do not take into account the fact that even non-pivotal generators may have some control over prices, since by withholding their capacity they force higher cost units to set the price. Large generators might find it profit maximising to use this strategy, even if they are not pivotal. This is the case, for example, of the generator controlling a large part of the base-load capacity in Figure 5.2, which can set the price at a level immediately below the cost of the peaking units even without being pivotal. This possibility is not captured by the basic pivotality indices.

\section{Technical constraints}

Standard pivotality measurements are generally based on the assumption that the generator can withhold up to its entire capacity at any time in order to increase the market-clearing price. In reality this may not always be feasible. For various technical or economic reasons, some types of electricity generation such as nuclear, hydropower, wind, and combined heat and power commonly cannot freely modify their output. Withholding the capacity of those units from the market, particularly at selected hours, may engender considerable costs or just be infeasible.

In the pivotality calculation, one can take into account the limited possibility of withholding must-run units by subtracting inflexible generation capacity from demand (Figure 5.5). Thus the pivotal capacity of Generator 1 , after taking into account its inflexible capacity, is: 


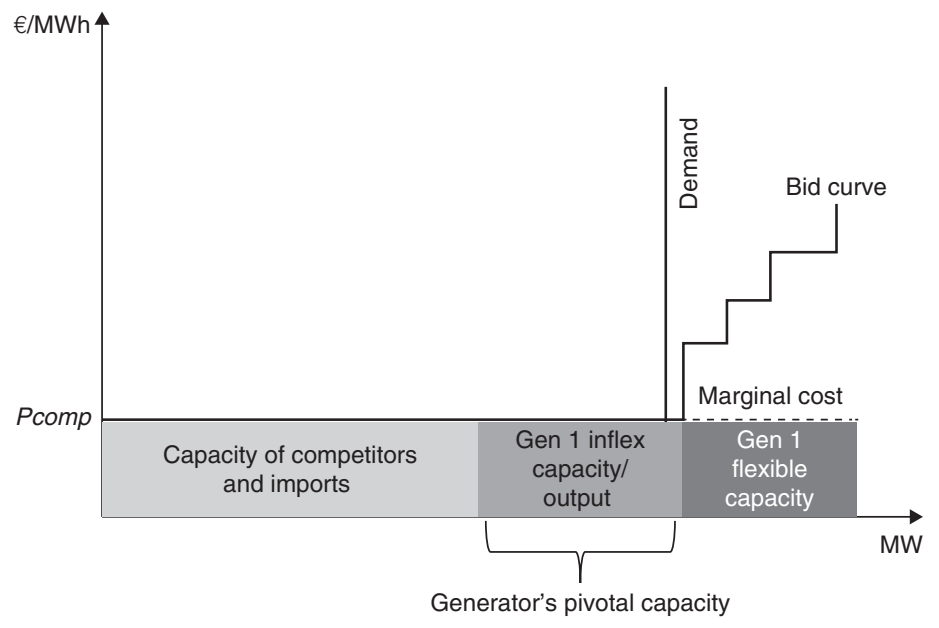

Figure 5.5 Pivotality adjustment for inflexible capacity

$$
\begin{gathered}
\text { Pivotal capacity }(\text { ability })_{1}=\text { Demand }_{-} \text {Capacity }_{-1} \\
- \text { All non-flexible output } \\
1,
\end{gathered}
$$

where Capacity $_{-1}$ is the total capacity of all the generators except 1 including total net import capacity, and All non-flexible output ${ }_{1}$ is Generator 1's production from must-run power plants.

\section{Incentives to increase prices}

Pivotality measures the ability of generators to raise prices but does not explicitly address the incentives to do so. Pivotal behaviour may entail a dramatic loss of sold volumes; in this case the pivotal strategy only turns out to be profitable if it induces an extremely high price. However there may be explicit or implicit limits on the price increase, such as the VoLL or lower regulatory price caps. A ceiling on the market-clearing price could render a price increase unprofitable for a pivotal generator if only a small share of its capacity is indispensible to meet demand. ${ }^{28}$

Furthermore, the pivotality calculation does not take into account the fact that the generator's incentive to increase the spot-market price may be limited if a significant share of its capacity is already committed to production at a fixed price. For example, this may be the result of long-term sales or a commitment to serve the generator's own final customers. In other terms, incentives to exercise market power depend on the generator's net position on the wholesale market.

The pivotality calculation can be adjusted to take into account the net 


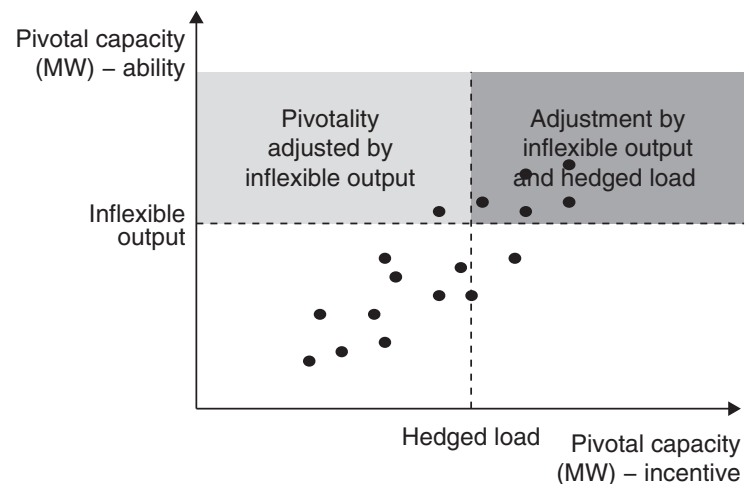

Figure 5.6 Adjustments to the pivotality analysis

position of the generator. For the purpose of assessing whether long term sales have an extreme impact on prices, the pivotal capacity of Generator 1 can be calculated as:

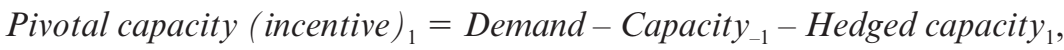

where Hedged capacity $_{1}$ is the share of Generator 1's capacity hedged by regulatory or contractual obligations.

Figure 5.6 shows examples of market-power assessments based on pivotality, adjusted for both flexibility and incentives. On the vertical axis we measure the generator's ability to exercise market power through the Pivotal capacity (ability) index. On the horizontal axis we measure the generator's incentives to exercise market power, through the Pivotal capacity (incentive) index. Each dot in the figure represents the pivotal capacities for the generator in one hour. The main source of differentiation between hours is the level of demand, but also the available capacity of competing generators and import capacity in different hours.

A generator that is pivotal when taking into account its total capacity, but whose pivotal capacity adjusted by must-run capacity and hedged load falls in the lower-left quadrant has neither the ability nor the incentive to have an extreme price impact in that hour. The upper quadrants represent hours where a generator has the ability to impact price using its flexible capacity. Finally, in the upper-right quadrant the generator has both the ability and the incentive to have an impact on price. The overall pivotality of the generator can be assessed by the number of hours of the year when the generator has both the ability and the incentive to be pivotal. 


\section{Pivotality benchmarks}

The pivotality analysis is becoming part of the standard toolbox of competition analysis as a first screening for market-power issues in wholesale electricity markets. However, no widely agreed standard is yet available regarding which level of pivotality should be regarded as an unambiguous signal of dominance or significant market power.

In the US, FERC employs two tests for the absence of market power: one based on market share and one based on pivotality. If a generator has less than a market share of 20 per cent and is not pivotal, FERC makes a rebuttable presumption that it does not possess significant market power, a necessary condition for lifting the cost-based bidding obligation on the generator. ${ }^{29}$ Some US markets employ pivotality-based tests as a trigger for market-power mitigation based on the bid caps. ${ }^{30}$

A competitive benchmark based on pivotality was proposed by the Market Surveillance Committee (MSC) on the California electricity market. It suggested using a pivotality-related Residual Supplier Index, or RSI, calculated in a given hour as:

$$
R S I_{1}=(\text { Total capacity }- \text { Generator 1's capacity }) / \text { Total demand } .
$$

A pivotal generator thus has an RSI of less than 1; the smaller the value of RSI, the more dependent the market is on the capacity of this generator, and thus the more market power the generator has. MSC has recommended that for a competitive electricity market the RSI should not be less than 1.1 for more than 5 per cent of the hours in a year. ${ }^{31}$

Another example of a competitive benchmark using pivotality measurements was proposed by the Italian antitrust authority (AGCM) during its investigation of a possible abuse of dominant position by Enel in 2005 and 2006. ${ }^{32}$ To identify whether Enel was dominant, AGCM calculated an index of Enel's pivotality in four macro zones ${ }^{33}$ of the Italian market where it was present. AGCM found that Enel was pivotal in 100 per cent of hours in the Macro South; 44 per cent of hours in the North; 29 per cent of hours in Sardinia; and 24 per cent of hours in Macro Sicily.

In addition AGCM considered cases in which Enel is not pivotal in a given market but is still pivotal by virtue of its simultaneous presence in more than one macro zone, impacting the flows between market zones. Applying this analysis, AGCM found that Enel was pivotal in each pair of macro zones: 95 per cent of hours in the North/Macro South, 91 per cent of hours in the Macro South/Macro Sicily, and 63 per cent of hours in Macro South/Sardinia.

Based on this analysis, AGCM concluded that Enel has extensive market power in all the macro zones. 


\subsection{MARKET POWER ASSESSMENT BASED ON GENERATOR'S MARKET BEHAVIOUR}

The structural measures discussed above provide information about firms' ability and incentives to impact the market price. However, they are not sufficient to identify whether market power has in fact been exercised.

Below we discuss various screening tests that have been developed to assess competitive behaviour in electricity markets. We also discuss the problems of estimating the variable cost of individual generators and the system marginal cost. Finally, we present a short review of studies of competitive behaviour in different countries.

\subsubsection{Screening Tests}

Economists and regulators have developed and implemented various screening tests in order to assess the exercise of market power in electricity markets. Generally these tests are based on comparison between the actual behaviour of firms and the actual market outcome with those that could be expected in a competitive environment where generators are expected to offer their capacity at variable cost, and market price is expected to be set at the marginal cost of energy in the system.

For example, a series of studies has analysed generators' behaviour, comparing the actual prices observed on the market with the competitive price estimates based on variable production costs. The costs of generators were assessed based on average heat rates and fuel prices, and together with generators' capacity were used to construct a short-run market marginal cost curve by stacking generators from the least expensive to the most expensive. The curve represents the supply curve that should prevail under competition. The hourly competitive price estimates were then obtained by intersecting these supply curves with hourly demand. To add realism to this modelling, import supply, operating reserve requirements and the probability of unit outages are also taken into account. ${ }^{34}$

Other tests involve analysing the data on generators' offers and sales. One such test, known as 'output gap analysis', checks whether at the observed market-clearing price a given firm has committed its production units efficiently. The test specifically verifies whether the units that have not been committed would have profitably produced at the observed market-clearing price. Failure to commit economic units (that is, presence of the output gap) can be considered capacity withholding aimed at increasing wholesale energy prices.

Another test using generator-specific bidding data involves comparing 
the level of the generator's offer curve in the market with the marginal cost of the generator's portfolio. The test verifies whether there are systematic deviations between the bidding curve submitted for the operator's generating capacity and the competitive marginal cost benchmark.

\subsubsection{Estimation of the Competitive Benchmark}

Tests of competitive behaviour in the electricity markets involve assessing the variable cost of energy produced by individual plants as well as the marginal cost of energy in the entire system. Electricity markets may seem to provide a large amount of data necessary for this exercise. The data on heat rates and the maximum production capacity of generating plants are often available. Information on fuel costs, which represent the bulk of variable production costs, can be obtained from price indices available publicly or from private reporting services. Thus, unlike other industries, estimating the costs of electricity generation would seem to be a straightforward and precise exercise.

However, even with these data, one may still fail to account for a large number of complexities of the electricity markets, which may lead to significant underestimation of the competitive generator offers as well as of the competitive market price. Cost-estimation approaches are usually static and do not take into account inter-temporal constraints faced by the generating units, such as ramp rates and minimum-run time constraints, or the unit commitment costs, such as start-up costs and minimum load costs.

Some units may face constraints on the total amount of energy that they can produce over a relatively long period, such as a month or a year. These are typically hydropower units with large reservoirs and thermal plants that operate under various environmental constraints. These units need to optimise the use of a limited amount of available energy over a long period, and to allocate production to the hours during that period with the highest prices. For energy-limited generators, producing in a given hour may entail forgoing profits for sales in other hours, that is, an opportunity cost. Therefore the profit-maximising (competitive) offers by energy-limited units generally depart from their variable production cost. Note that assessment by generators of opportunity costs considers the profits that would be obtained by selling their energy endowment at a different time, that is, the future evolution of the market-clearing price. $^{35}$

All these details of the actual production constraints and costs impose significant restrictions on the combined production possibility frontier of generators. The actual marginal cost of energy may be considerably 
higher than the marginal cost estimated without taking such restrictions into account.

Finally, unlike the US markets, in most European electricity markets the market bid format is simple, and the clearing mechanism does not take into account the entire set of operational constraints of power plants. In these markets, accurate assessment of the costs and competitive behaviour of generators would involve using the actual operational data from portfolio optimisation operations performed by generating companies.

\subsubsection{International Comparison of the Reference Price-cost Margin}

Studies of market-power behaviour are often based on the relative margin between the observed market price and competitive price benchmark, which is often assumed to be equivalent to the energy marginal cost estimate. In Table 5.1 we present a summary of several such behavioural metrics performed by competition authorities, energy regulators and as part of academic studies in Europe and the United States.

Table 5.1 International comparison of price-cost margin estimations

\begin{tabular}{lcll}
\hline Market & $\begin{array}{c}\text { Price-cost } \\
\text { margin }(\%)\end{array}$ & Period & Source \\
\hline Germany & 27 & $2003-2005$ & EC Energy Sector Inquiry 2007 \\
Spain & 21 & & \\
Netherlands & 6 & & \\
UK & 11 & & \\
UK & $20-25$ & $1992-1994$ & Wolfram 1998 \\
Germany & 21 & 2004 peak & Hirschhausen and Weigt 2007 \\
Italy & $10-20$ & 2004 peak & $\begin{array}{l}\text { Perekhodtsev and Baselice 2008 } \\
\text { PJM }\end{array}$ \\
California & 3 & 2008 & US wholesale market monitoring \\
\hline
\end{tabular}

Sources:

a Enquête menée par la Commission européenne en vertu de l'article 17 du règlement (CE) $n^{\circ} 1 / 2003$ sur les secteurs européens du gaz et de l'électricité (rapport final), 10 January 2007, \{SEC(2006) 1724$\}, \operatorname{COM(2006)} 851$ final.

b Wolfram, C., 1999. 'Measuring Duopoly Power in the British Electricity Spot Market', American Economic Review, 89(4) September, 805-26.

c Weigt and Von Hirschhausen, 2007 (see n. 34).

d Perekhodtsev, D. and Baselice, R., 2008. 'Measuring Competitive Behaviour in the Italian Power Exchange', paper presented at the 31st IAEE International Conference, Istanbul, Turkey, 18-20 June.

e Department of Market Monitoring CAISO, 2008. Market Issues and Performance; Annual Report Monitoring Analytics, LLC, 2008, State of the Market Report for PJM. 
The table suggests a wide range of positive margins and may indicate a variety of competitive conditions. However, it should be borne in mind that these studies represent very different approaches to evaluating the competitive benchmark and estimating the system marginal cost. In estimating the competitive benchmark, the studies range in accuracy from evaluation of the system marginal cost from the static supply curve estimated from the national generating portfolio data, to the studies performed by the market monitors in the US where the competitive benchmark was estimated from the detailed data on generators bids, and the format of bids provides complete information about production constraints on plants.

Regulators do not usually use these margins as a trigger for intervening and taking action against abusive market behaviour. An exception is provided by the MSC of the Californian market, which suggested using a 10 per cent threshold of the average annual margin. If the margin is below this level, the MSC considers that prices are just and reasonable and that the risk of market-power exercise is limited. It would suggest a regulatory intervention if the price-cost margin exceeded 10 per cent. During the California power crisis in 2000, when high wholesale prices induced the regulator to intervene, the average price-cost margin reached 40 per cent, that is, far above the threshold.

\subsection{MARKET-POWER MITIGATION MEASURES}

In some countries, liberalisation of the wholesale electricity markets has been accompanied by the introduction of market-power mitigation measures. In this section we discuss the main types of market-power mitigation mechanisms.

\subsubsection{Divestiture, Contracts and Virtual Power Plants}

\section{Generation capacity divestiture}

Divestitures were implemented in some European countries when electricity generation was liberalised - as in Italy and the UK in the 1990s - in order to mitigate the market power of the former monopolist. ${ }^{36}$ Generation capacity divestitures have also been accepted as a remedy by competition authorities in several cases of mergers and abuse of dominance. ${ }^{37}$

Figure 5.7 illustrates the impact of the divestment of generation capacity by a dominant firm facing competition from a price-taking fringe. Recall that the residual demand function represents the demand for electricity net of the fringe's production, at each price level. Divestiture of 

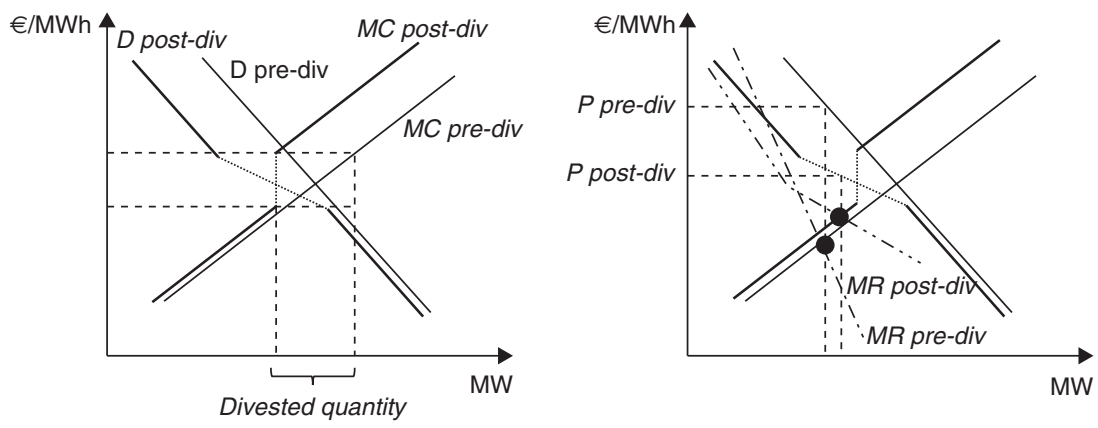

Figure 5.7 Impact of generation capacity divestment

the dominant firm's capacity has three effects. First, it increases the dominant firm's variable costs. Part of the marginal cost curve of the dominant firm translates upwards, as the segment corresponding to the divested capacity is removed. Second, the residual demand for the dominant firm reduces, as the divested generation capacity is offered in the market by the new owners. This effect is shown in the figure as a translation to the left of the residual demand. Third, the divestiture changes the slope of the residual demand, since the divested capacity is offered competitively - at prices equivalent to the variable costs - by the fringe.

The right panel of the figure shows the pre- and post-divestiture marketclearing price. The dominant firm selects the profit-maximising volume and quantity by behaving as a monopolist on the residual demand curve, that is, at a level such that the revenue from selling an additional unit and the incremental cost of supplying it are equal. As a consequence of the divestiture, the profit-maximising price for the dominant firm therefore reduces.

Federico and López (2009), ${ }^{38}$ show that the divestiture's impact on the market-clearing price depends on both the size and the position of the divested capacity on the dominant firm's cost curve. They show that the largest price reduction is achieved by divesting capacity with marginal cost close to the post-divestiture market-clearing price. The most effective divestment policy entails transferring capacity that: (i) in the pre-divestment equilibrium would not be used, because offered by the dominant firm at a price above the variable cost, and (ii) in the postdivestment equilibrium would be activated, once offered competitively by the fringe.

As shown in the figure, the optimal divestment policy brings the dominant firm to select the profit-maximising price on the portion of the 

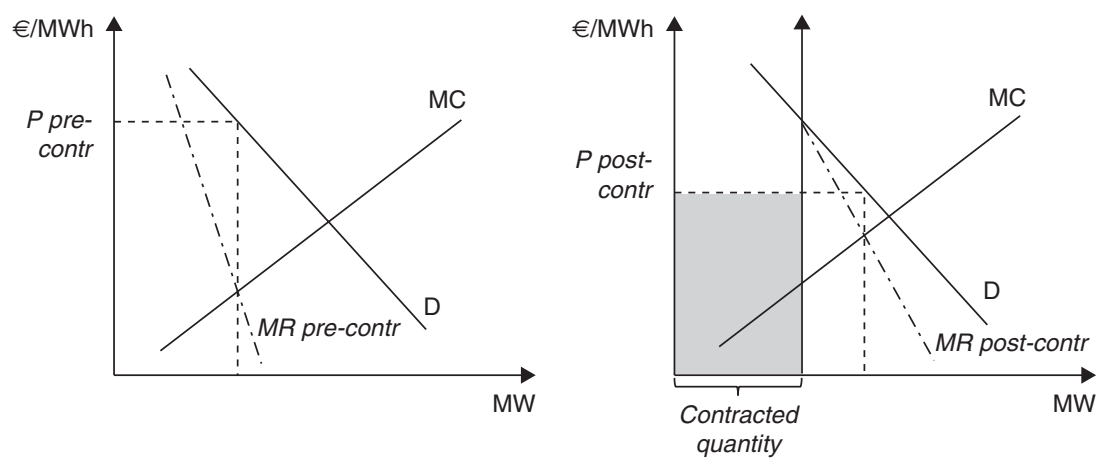

Figure 5.8 Impact of long-term contracts

residual demand curve that was flattened by the transfer of assets to the fringe. ${ }^{39}$

\section{Long-term contracts}

A long-term contract commits the generator to deliver a certain production volume at a predetermined price at a future date. ${ }^{40}$ Figure 5.8 shows how a forward sale impacts on the dominant firm's profit-maximising strategy in the spot market. The spot-market equilibrium that would result if the dominant firm were not contracted is shown in the left panel. The long-term contract makes the firm's revenues from the contracted quantity independent of the spot-market price. In other words, the longterm contract simultaneously reduces the size of the spot market and the generation capacity that the dominant firm can offer in that market. We represent this effect in the right panel of the figure as a shift of the vertical axis. The forward position reduces the incremental revenue for each production level that the dominant firm would obtain by increasing the price. This happens because the contracted volumes are sold at a fixed price. As a consequence the spot-market price that maximises the dominant firm's profit is lower than if the contract were absent. This provides the basis for requiring the dominant generator to commit to forward sales. Such a measure was implemented, for example, in Alberta (Canada). ${ }^{41}$

Market power mitigation through financial contracts presents some advantages over asset divestiture. First, it does not risk causing technical inefficiencies by splitting the physical generation capacity among multiple firms. Second, it may be easier to implement than asset divestiture. Finally, measures based on financial contracts can be easily terminated, once the structural conditions driving the market-power concerns have been alleviated by entry in the market of other generators. 
However, forward contracts can be less effective than structural measures. First, in a repeated context, the dominant firm may find it profitable to set spot prices higher than those maximising short-term profits, in order to influence the outcome of future sales of forward contracts. The price for the forward contracts will be higher if the buyers expect higher spot market prices during the delivery period. If the dominant firm could commit to the contracts' buyers to set the monopoly price in the spot market throughout the delivery period, the profits for the dominant firm from the forward sales would be the same as those achievable on the spot market without the mitigation measure. More generally, the dominant firm might find it optimal to forgo some spot market profits in order to influence the value of the forward contracts sold in the next round.

Second, as we discuss next in the context of virtual power plants, forward contracts yield spot market prices higher than those that would prevail if the same level of capacity was divested.

\section{Virtual power plants}

A virtual power plant (VPP) is an option contract allowing the holder to buy a certain volume of electricity at a predetermined price, known as the 'strike price', and resell it at the spot price. The option will then be exercised whenever the spot market price is higher than the strike price. In other words, a VPP has the same effect as a forward contract when the spot-market price is above the strike price, and produces no effect when the spot-market price is below the strike price.

The VPP reduces the incentives for the dominant firm to exercise market power, by making the profit on the contracted quantity independent of the spot price. Conversely, when the spot price is below the strike price the VPP has no impact on the firm's profit.

Note that the forward contracts analysed in the previous section can be interpreted as VPP with a zero strike price, which will therefore always be exercised. Therefore, other things being equal, a VPP will have a marketpower mitigation effect that is at most equivalent to that of a forward contract for the same volume.

Federico and López (2009) compare the effect on the spot price of the transfer of a set of generation assets with that of VPPs hedging the same assets. ${ }^{42}$ They find that the VPPs have a milder market-power mitigation effect than divestiture. This happens because, contrary to divestiture, VPPs do not affect the production capacity available to the competitors. As a comparison between Figures 5.7 and 5.8 reveals, both measures cause a shift in the residual demand curve faced by the dominant firm, but only the divestiture changes its slope, by removing from the dominant firm the right to set the offer price in the spot market for the divested capacity. 

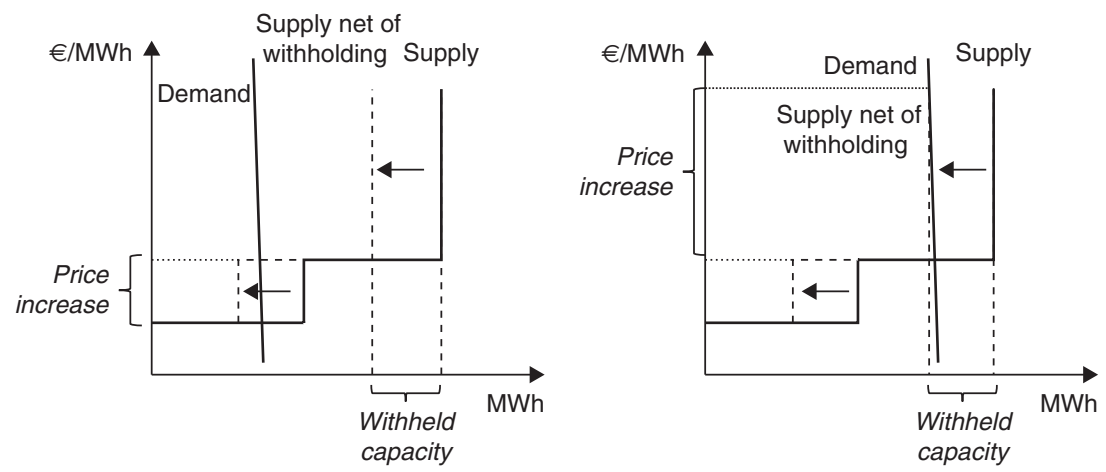

Figure 5.9 Effect of capacity withholding on market price

\subsubsection{Price Caps}

An overall price cap is implemented in most electricity spot markets, at least in the form of an administratively set price applicable to the transactions that take place under conditions of scarcity, when there is physical rationing of demand.

Setting a price cap below the VoLL may effectively mitigate market power, because spot electricity markets are particularly vulnerable to market power when demand approaches the available generation capacity. Since when the system is tight both demand and supply are price inflexible, withholding even a small amount of generation capacity from the market may result in a dramatic price increase. This holds especially if withholding capacity causes the market-clearing price to rise above the system marginal cost.

Figure 5.9 compares the impact of capacity withholding under contrasting conditions. In the left panel demand is low relative to the available generation capacity; capacity withholding therefore moves the marketclearing price along the system variable cost, to the variable cost of a more expensive generator. In the right panel the existing generation capacity is close to full utilisation; in this case capacity withholding induces scarcity, and the market-clearing price moves from the variable cost of the most expensive generator to the much higher level necessary to ration demand. ${ }^{43}$

As the figure shows, when the system is tight even relatively small generators may have the incentive and the ability to set extremely high prices, because all it takes to bring about a large price increase is a small reduction in supply.

Ruling out the possibility that the market-clearing price departs significantly from the system, marginal cost reduces the incentives to exercise 
market power. In this case the price increase caused by capacity withholding is relatively limited, even if the system is tight.

However, setting an overall price cap lower than the VoLL also prevents the price reaching the efficient level in genuine conditions of scarcity, making it impossible to remunerate the capital invested in (the efficient level of) generation capacity. For this reason, capacity support schemes are generally implemented together with price caps. ${ }^{44}$

Note, finally, that an overall price cap may lead to inefficiency in the event that demand shows some elasticity at a price above the cap. In this case the cap prevents the market-clearing price from rising to the level that rations demand in situations of scarcity, increasing the need for physical rationing.

\subsubsection{Bid Mitigation}

Spot-market operators in the US implement ex ante market-power mitigation mechanisms that force the bids of certain generators to predefined reference levels when certain conditions occur. ${ }^{45}$

The first stage of automatic mitigation procedures is a structural test. In some implementations the structural test directly triggers enforcement of the caps on offer prices. For example, the PJM Interconnection ${ }^{46}$ tests whether any three suppliers are jointly pivotal for resolving any transmission constraints. ${ }^{47}$ The three pivotal supplier assessment for a transmission constraint starts with a baseline scenario, that is, the generator dispatch and corresponding power flows on the network that would take place if the market were cleared without enforcing the relevant transmission constraint. ${ }^{48}$ The baseline scenario is then used to check whether the constraint could be resolved in the event that all three pivotal suppliers refused to change their output from the base levels, by re-dispatching other units with incremental costs less than or equivalent to 150 per cent of the baseline market-clearing price. Finally PJM applies offer capping to the units that fail the three pivotal supplier test. This type of screening and bid mitigation is performed on both the day-ahead and real-time markets.

In other markets the structural test serves as a first screen to determine whether to subject specific suppliers to further tests, which may then trigger bid mitigation. The structural test is specifically used to identify areas of the network that are presumed to be prone to non-competitive outcomes due to transmission limitations. In competition policy terms, the structural test can be regarded as identifying the relevant market, a preliminary step to the competitive assessment carried out through additional tests. Two types of additional tests are then implemented. Conduct 
tests compare a unit's offer to a predefined threshold (for example, 300 per cent above the unit's cost-based reference price). Impact tests detect whether bids that failed the conduct test increase the clearing price above the level that would result if the reference prices were bid. Conduct and impact tests are carried out for all supply resources located in the system operator's control area. However, more stringent conduct and impact thresholds apply to generators located in the potentially non-competitive areas identified by the structural tests. If these tests are failed, bid mitigation is implemented.

The same conceptual framework is applied in the US capacity markets, with two additional features related to the specific nature of these markets The first is that the cap on the offers in the capacity markets reflects units' expected profits in the energy and operating reserve markets. Recall from Chapter 3 that capacity markets are a means to support generators' income, in the event that the prices prevailing in the energy and ancillary service markets are too low to attract an adequate level of investment. Therefore, the higher the income that a unit is expected to obtain by selling energy and operating reserve, the lower the reference price for that unit in the capacity market. The second feature is that entrants are generally regarded as competitive price setters and therefore not subject to the mitigation mechanism.

Besides generators' offer prices, other practices are monitored in some US markets. These include the physical withholding of generation resources, uneconomical production that cannot be justified and load bidding or virtual bidding practices that create unwarranted divergence between day-ahead and real-time prices. The physical withholding of capacity from the market has the same effect on the market price as offering it at prices above the market-clearing level. Uneconomical production, typically aiming at creating congestion, is detected by comparing the market-clearing price with the unit's reference cost level. Load-serving entities may also exercise (buyer) market power in the day-ahead market by consistently scheduling load in real time. Finally, virtual bids, meant to ensure the consistency of day-ahead and real-time prices, may be misused in order to induce divergences between day-ahead and real-time prices that are not justified by the fundamental market conditions and information available to market participants.

\subsection{SELECTED CASES}

In this section we discuss cases in which the technical features of electricity are particularly influential in shaping competition policy issues. 


\subsubsection{Market Power and Market Design: Bidding in Situations of Congestion}

In most European countries forward electricity markets, including the day-ahead and the intraday markets, are run as if transmission capacity is unlimited. In the event that the power flows implementing the market outcome violate one or more network constraints, generators and possibly load-serving entities are paid to modify the level of production and consumption they scheduled after the unconstrained trading stage. Selection of the offers to modify the production and consumption programmes takes place in the real-time market or in an ad hoc re-dispatch market.

In Chapter 4, Section 4.4 we showed that this feature of the market design has an impact on the generators' profit-maximising offer strategy. Consider first, generators located in import-constrained areas, where production will have to be increased by the system operator at the re-dispatch stage in order to address the network constraint, and where the clearing price of the re-dispatch market is therefore higher than the clearing price of the forward markets. Generators located in the import-constrained areas will maximise their profits by withholding capacity from the unconstrained forward markets and offering it on the re-dispatch market, where its value is higher. Specifically, these generators have an incentive to offer their production on the forward markets at the price they expect will clear the re-dispatch market in the area where they are located.

A matching incentive holds in the export-constrained areas of the network, where production will have to be reduced by the system operator at the re-dispatch stage in order to address the network constraint, and where the clearing price of the re-dispatch market is therefore expected to be below the unconstrained clearing price of the forward markets. Generators located in export-constrained areas will maximise their profits by selling on the forward markets at any price higher than the expected clearing price of the re-dispatch market, irrespective of their variable costs. ${ }^{49}$ By doing so, these generators will not produce, but they will cash in on the difference between the price obtained from their forward sales and the price that they pay to the system operator at the re-dispatch stage to reduce production.

As we argued in Chapter 4, Section 4.4.2, these incentives hold even for generators that do not have any market power. Nevertheless, generators' bidding behaviour in the event of congestion has been subject to scrutiny by the competition authorities as potential abuse of market power in some European markets. In Spain between 2002 and 2005 the competition authority brought a series of legal cases against generators whose bids in the day-ahead market reflected the expected price in the re-dispatch 
market. ${ }^{50}$ The Spanish competition authority regarded the offer strategy as an abuse of dominant position. ${ }^{51}$

In the UK the energy regulator Ofgem, which is also in charge of enforcing competition law in the electricity industry, has been concerned that the increase in congestion costs on the interconnector between Scotland and England was caused by abusive bidding behaviour. Ofgem examined the situation in September and October 2007, and found evidence that Scottish generators submitted lower bids in the balancing market than comparable generators located in England during periods of congestion on the Anglo-Scottish boundary in the direction of England, that is, when Scotland was export constrained. The Scottish generators were also found to have submitted higher offers than comparable plants located in England when congestion was in the direction of Scotland, that is, when Scotland was import constrained. The generators' behaviour also included 'the apparent withholding of in-merit plants during import constraints despite positive spreads being available in the forward market'. Other periods were identified in which generators appeared to be running plants out of merit during export constraints. ${ }^{52}$

Ofgem concluded that the observed behaviour provided no basis for an abuse of dominance allegation within the standard competition policy framework. Interestingly though, Ofgem has sought an extension of its powers, allowing it to sanction this kind of behaviour within a different legal framework. ${ }^{53}$

In other contexts, notably Germany and recently Spain, the problem is considered a regulatory issue, and proposals are put forward to address it by regulating offer prices in the re-dispatch market. ${ }^{54}$

The issues discussed in this section are a consequence of the high level of product standardisation implemented in the European electricity spot markets. In the forward markets, electricity produced at all network locations is conventionally considered as the same product, and therefore exchanged at the same price, even if network constraints make it physically impossible to substitute production at one node with production at another. However, when it comes to physical delivery, this fiction cannot be maintained: the production programmes selected by the market participants at the unconstrained stage have to be modified if some network security constraints are not met. At this point, the price for electricity at each node is driven by the physical market fundamentals, that is, it reflects the real marginal cost of meeting the incremental consumption at that node.

Measures that prevent market participants' bids and offers from reflecting the impact of network constraints on the value of electricity can hardly be considered market-power mitigation measures. Rather they force 
(competitive) generators to behave irrationally, in order to mitigate the adverse impact on customers of the artificial geographical product standardisation implemented in the forward markets.

\subsubsection{Re-dispatch Cost and Cross-border Capacity: The Swedish Interconnector Case}

In most European countries, transmission congestion within national borders is dealt with via re-dispatch. Cross-border congestion, on the other hand, is generally managed by limiting the volume of exchanges that cause cross-border flows. This is achieved by allocating market participants a set of feasible transmission rights, the volume of which is jointly agreed by the relevant national system operators. The Nordic electricity market, comprising the territory of Norway, Sweden, Finland and Denmark, presents an interesting example of a mix of the two approaches.

Part of transmission congestion in the Nordic exchange is dealt with by dividing the area into market zones. The market participants make bids and offers that specify in which zone the electricity purchased and sold will be respectively produced and consumed. The market-clearing price differs across zones in the event of congestion. Until November 2011 the market zones were the national territories of Sweden and Finland. There are two zones in Denmark and four in Norway. ${ }^{55}$ Congestion within each market zone is dealt with via re-dispatch by the national system operator.

In this context, national system operators may face a trade-off between the cost of domestic re-dispatch and the level of cross-border transmission capacity allocated to the market. It may be the case that by limiting the cross-border trades a system operator can reduce the need for domestic re-dispatch. This situation is illustrated in a highly stylised setting in Figure 5.10. The transmission networks of two neighbouring countries, A and $\mathrm{B}$, include, respectively, two and one nodes. The transmission capacity of the lines and the supply and demand, which as usual we assume is

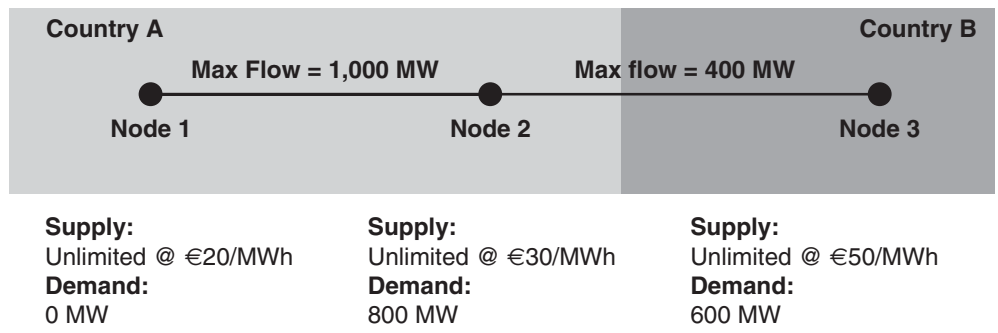

Figure 5.10 Grid representation 


\begin{tabular}{|c|c|c|c|c|c|}
\hline \multicolumn{4}{|c|}{ Country A } & & \multirow[t]{2}{*}{ Country B } \\
\hline \multirow{2}{*}{$\begin{array}{l}\text { ANTE } \\
\text { RD }\end{array}$} & \multicolumn{3}{|c|}{ Max flow = 1,000 MW } & lax flow $=400 \mathrm{MW}$ & \\
\hline & Node 1 & Actual flow 1,200 MW & Node 2 & $\mathrm{NTC}=400 \mathrm{MW}$ & Node 3 \\
\hline \multicolumn{3}{|c|}{ Production: } & Production: & \multicolumn{2}{|c|}{ Production: } \\
\hline \multirow{2}{*}{\multicolumn{3}{|c|}{$\begin{array}{l}\text { 1,200 MW } \\
\text { Consumption: }\end{array}$}} & $\mathrm{OMW}$ & \multicolumn{2}{|c|}{$200 \mathrm{MW}$} \\
\hline & & & Consumption: & \multicolumn{2}{|c|}{ Consumption: } \\
\hline \multicolumn{3}{|c|}{$0 \mathrm{MW}$} & $800 \mathrm{MW}$ & \multicolumn{2}{|c|}{$600 \mathrm{MW}$} \\
\hline \multirow{2}{*}{\multicolumn{3}{|c|}{$\begin{array}{l}\text { Net-out ante-RD: } \\
\text { 1,200 MW }\end{array}$}} & \multirow[t]{2}{*}{ Net-out ante-RD: } & \multicolumn{2}{|c|}{ Net-out ante-RD: } \\
\hline & & & & $-400 \mathrm{M}$ & \\
\hline \multirow{2}{*}{\multicolumn{3}{|c|}{$\begin{array}{l}\text { Market-clearing price: } \\
€ 20 / \mathrm{MWh}\end{array}$}} & \multirow{2}{*}{$\begin{array}{l}\text { Market-clearing price: } \\
€ 20 / \mathrm{MWh}\end{array}$} & \multirow{2}{*}{\multicolumn{2}{|c|}{$\begin{array}{l}\text { Market-clearing price: } \\
€ 50 / \mathrm{MWh}\end{array}$}} \\
\hline & & $€ 20 / M$ & & & \\
\hline
\end{tabular}

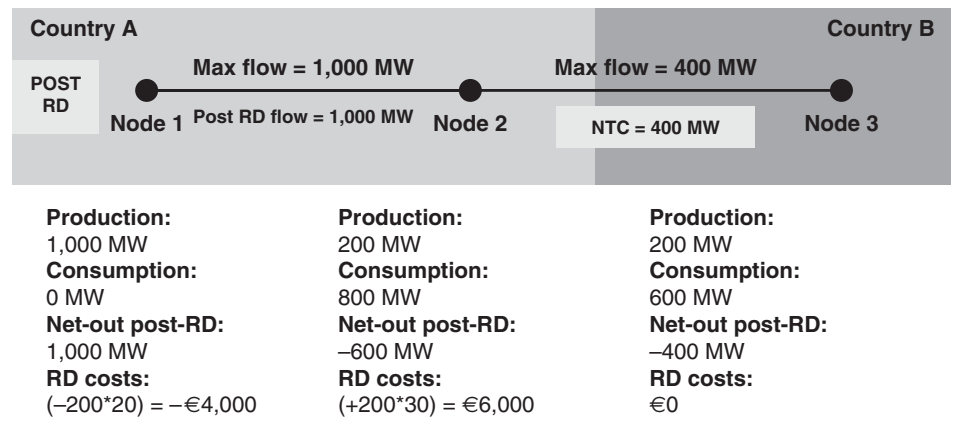

Figure 5.11 Market outcomes with net transfer capacity $($ NTC) $=$ $400 \mathrm{MW}$

price inelastic, are indicated in the figure. Congestion between the two countries is managed by allocating a feasible set of transmission rights to the market. Congestion within each country is managed via re-dispatch.

Figure 5.11 illustrates the market outcome in the event that the system operators decide to allocate the market $400 \mathrm{MW}$ transmission rights between country A and country B, the largest feasible set of transmission rights. Under that assumption the market equilibrium is such that 400 MW of country B's demand and country A's entire demand are supplied by generators connected at node 1 , the cheapest producers. The remaining 200 MW demand in country B is supplied by domestic generators, connected at node 3 . The market-clearing price is $€ 20 / \mathrm{MWh}$ in country A, equivalent to the unconstrained system marginal cost in the country, and $€ 50 / \mathrm{MWh}$ in country B.

The 1,200 MW flow between nodes 1 and 2 implementing this market outcome is infeasible. This congestion, being internal to country A, is managed through re-dispatch. Country A's system operator buys $200 \mathrm{MW}$ 


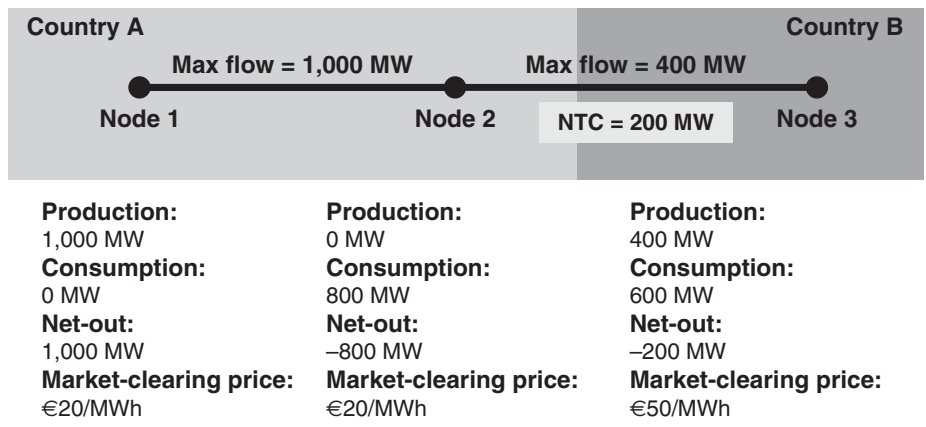

Figure 5.12 Market outcome with NTC $=200 \mathrm{MW}$

at node 2 at $€ 30 / \mathrm{MW}$ and sells the same amount at node 1 at $€ 20 / \mathrm{MWh}$. This re-dispatch reduces the flow between nodes 1 and 2 to a feasible 1,000 MW. The clearing prices of the re-dispatch market are $€ 30 / \mathrm{MWh}$ and $€ 20$ / MWh, respectively, at node 1 and node 2 . The system operator bears the $200 *(30-20)=€ 2,000$ re-dispatch cost.

Figure 5.12 shows the market outcome if only $200 \mathrm{MW}$ of transmission rights between countries $\mathrm{A}$ and $\mathrm{B}$ were allocated to the market participants. In this case only $200 \mathrm{MW}$ of country B's demand adds to country A's demand, which is met by the generators connected at node 1. The market outcome now results in a 1,000 MW power flow along the line connecting nodes 1 and 2. This flow is feasible, therefore no re-dispatch is required in country A. By limiting the volume of crossborder transmission rights, the system operator of country A therefore saves on re-dispatch costs. However, the total generation cost is not minimised. ${ }^{56}$

Furthermore, different levels of cross-border capacity lead to different distributions of the total surplus among the generators and consumers of the two countries, as well as the transmission right-holders. ${ }^{57}$

In April 2009 the European Commission opened a case against the Swedish system operator Svenska Kraftnät (SvK). The Commission was concerned that SvK was limiting the amount of export transmission capacity across Sweden's borders, with the objective of relieving transmission congestion on its internal network. According to the Commission, this would favour consumers in Sweden over consumers in neighbouring member states by reserving domestically produced electricity for domestic consumption. ${ }^{58}$ The Commission's preliminary assessment found that this behaviour could represent an abuse of dominant position on the Swedish electricity transmission market, as it discriminated between domestic and export electricity transmission services. ${ }^{59}$ 


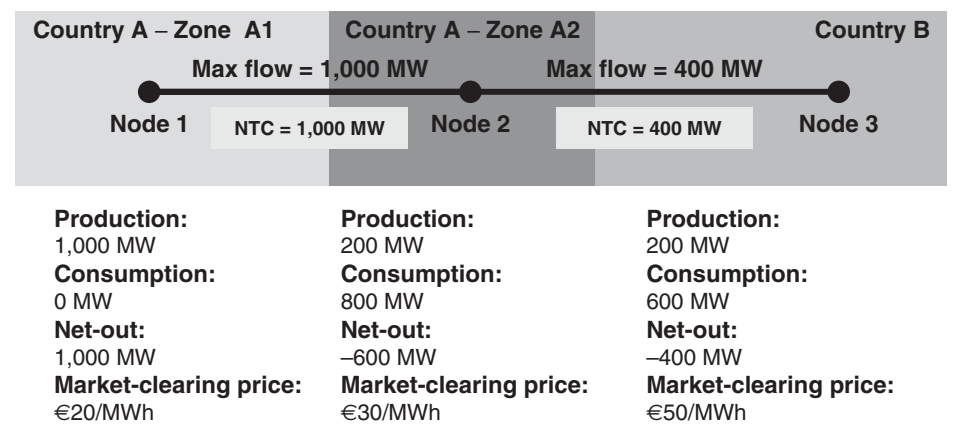

Figure 5.13 Market output after the splitting of country A into two market zones

In order to address these concerns, SvK offered to subdivide the Swedish transmission system into two or more bidding zones, and to manage domestic congestion without limiting trading on the interconnectors. ${ }^{60}$ In our example, this would amount to establishing two market zones within country A, as shown in Figure 5.13.

The system operator now allocates 1,000 MW transmission rights between the two market zones in country A and $400 \mathrm{MW}$ between zone A2 and country B. The market outcome is shown in the figure. The demand faced by the cheapest generators located at node 1 is now limited to 1,000 MW by the available transmission rights. The second cheapest generators located in node 2 are activated to serve the remaining $200 \mathrm{MW}$ demand in country A, limited by the available transmission rights from zone A2 to country B. Since both interfaces are congested, a different price clears the market in the each zone. No re-dispatch is necessary.

The solution proposed by the Swedish system operator eliminates discrimination, since cross-border and domestic transactions compete on a level playing field for the use of transmission resources. Note, incidentally, that the mechanism leads to the efficient allocation of transmission capacity and to minimisation of total supply costs. Therefore the system operator's proposal reconciles the non-discrimination objective and the efficiency objective, the standard reference for market design.

From an institutional perspective, in the Swedish Interconnector case competition policy has entered a territory traditionally within the domain of energy policy. By addressing the problem within the competition policy framework, the Commission has taken the regulatory system (and the regulators) out of the picture. The Commission sees limiting cross-border capacity in order to reduce re-dispatch cost as an abuse of dominant position under Article 102 of the Treaty. In so doing: 
- the system operator's dominant position is established based on its monopoly position in the supply of transmission services, without reference to the regulatory framework that sets the system operator's objectives and incentives, and

- the abuse is characterized in terms of discrimination between domestic transactions and cross-border transactions without reference to efficiency issues, which would be the main focus of a regulatory approach.

\subsubsection{Abuse of Dominant Position in Related Markets}

Generally, wholesale spot prices are not directly passed on to final consumers through retail prices. Retail prices are typically fixed for a relatively long period, for example a year or a quarter, and reflect the wholesale prices expected when the retail contract is signed. ${ }^{61}$

Retailers hedge against wholesale price volatility by forward buying the volume of electricity that they expect to retail. Most retailers, however, are vertically integrated in the generation business, which provides a natural hedge against wholesale price volatility, by making them at the same time buyers and sellers on the wholesale market.

A congestion management system based on locational prices adds a geographical dimension to the hedging problem faced by the retailer. It needs to fix the price of the electricity in the market zone where its clients consume by purchasing forward contracts with delivery in that market zone. Alternatively, if the retailer owns generation capacity in a different zone, it can buy long-term transmission rights enabling it to 'move' electricity from the market zone where it can generate it to the market zone where its clients consume it.

The Italian electricity spot market began operating in 2004. At that time forward trading was limited and long-term transmission rights were not available. The main retailers were also generators. Congestion management was, and still is, carried out by splitting the Italian territory into market zones, the prices of which vary in case of congestion.

The peculiar feature of the Italian congestion management system is that locational prices are assessed for production only, while all consumption is charged a uniform nationwide price. The uniform national price (PUN) is calculated as the weighted average of the market-clearing prices of all the market zones, with weighting the equivalent of the demand in each market zone. ${ }^{62}$

Intuitively, this approach amounts to placing all consumers in a virtual market zone connected to the production zones in a way such that the clearing price in the virtual zone is the weighted average of clearing prices 


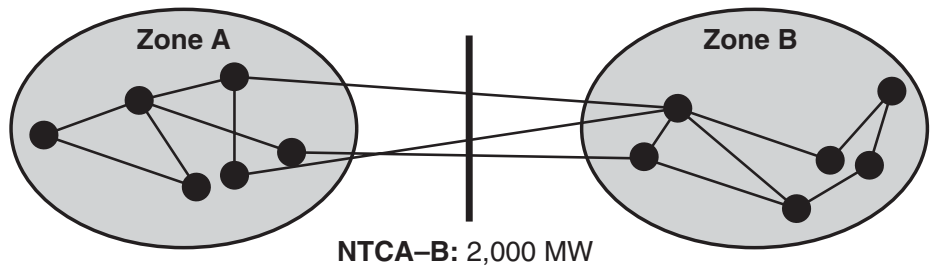

Supply A: $8,000 \mathrm{MW}$ Demand A: 6,000 MW Supply B: $1,000 \mathrm{MW}$ Price A: $€ 45 / \mathrm{MWh}$ Demand B: 3,000 MW Price B: $\quad € 60 / M W h$

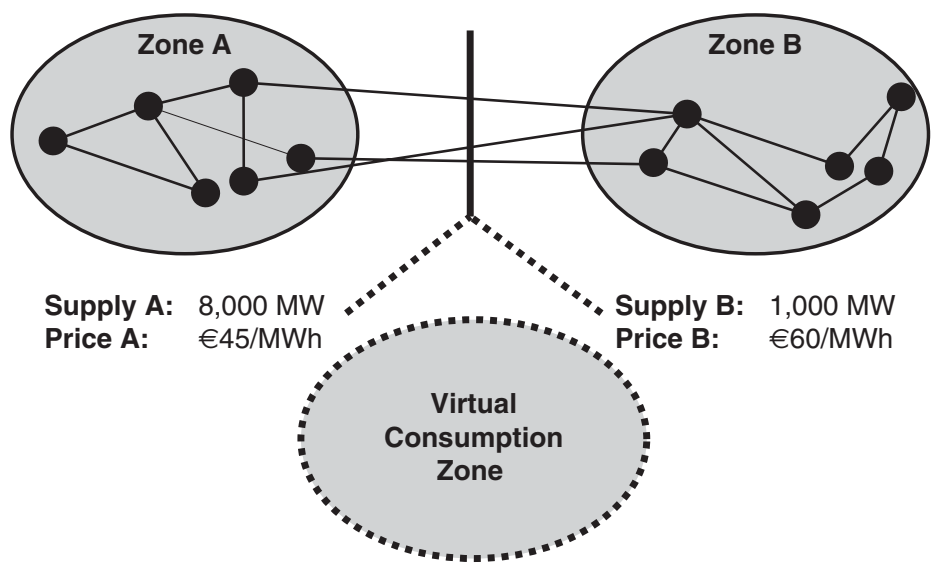

Demand: 9,000 MW

Price (PUN): $45 \frac{6,000}{9,000}+60 \frac{3,000}{9,000} € \mathrm{MWh}$

Figure 5.14 Price-setting mechanism in the Italian spot market

in the real zones, as illustrated in Figure 5.14 for the simplest two-zone market. The upper panel of the figure shows the market outcome resulting from the zonal market-clearing algorithm. The lower panel shows the market outcome obtained with the clearing algorithm implemented in Italy.

The transmission capacity between the production zones and the virtual consumption zone is allocated by a power exchange via an implicit auction, as illustrated in Chapter 4, Section 4.3.2. Bilateral transactions between a generator and a consumer attract a congestion fee equivalent to the difference between the uniform national price and the market-clearing 
price in the zone where production takes place. This congestion fee makes it indifferent for market participants to implement the transaction bilaterally or through the power exchange. ${ }^{63}$

Long-term financial transmission rights between the production zones and the virtual consumption zone are issued by the Italian system operator and allocated to the market. However, for simplicity of exposition, we illustrate the competition case with reference to a bilateral transaction between a supplier and its customers.

We consider a supplier retailing $90 \mathrm{MW}$ to end-consumers under fixedprice annual contracts. We assume for simplicity's sake that no forward wholesale contracting takes place in the market and that the supplier controls some generation capacity. It is easy to verify that, in order to lock in the retail margin, that is, to make its profit independent of spot prices, the supplier must be able to produce $60 \mathrm{MW}^{64}$ in zone A and $30 \mathrm{MW}^{65}$ in zone B. Since the supply takes place via a bilateral contract the spot prices only enter the retailer's profit function via the congestion charge.

The unit congestion fee for a bilateral contract with production in zone $\mathrm{A}$ is $(P U N-P A)$, irrespective of where consumption takes place. For a bilateral contract with production in zone $\mathrm{B}$ the congestion fee is $(P U N-P B)$. Hence by producing $60 \mathrm{MW}$ in zone A and $30 \mathrm{MW}$ in zone $\mathrm{B}$ the retailer pays an average congestion fee of $60 / 90 *(P U N-P A)+$ $30 / 90^{*}(P U N-P B)=0 € / \mathrm{MWh}$. In other words, by allocating production across the market zones in the same proportion as the weighting of the zonal prices in the PUN, the retailer gains a perfect hedge against the volatility of spot market prices.

Consider now a retailer owning generation capacity only in zone A. ${ }^{66}$ By producing the entire $90 \mathrm{MW}$ supplied to its customers in zone A, the retailer pays unit congestion charge $P U N-P A=1 / 3^{*}(P B-P A)$. In this case the congestion fee paid by the retailer to supply its clients depends on the locational prices. If the spot prices turn out to be different from those expected at the time of committing to the fixed supply price, and especially if the difference between the spot prices in the different locations was wrongly anticipated, the retailer's profits will depart from the expected level.

In April 2005 the Italian competition authority started proceedings against Enel S.p.A., the main generator and retailer in the Italian market. ${ }^{67}$ The competition authority identified some features of the company's bidding behaviour in the spot market that did not appear to reflect genuine profit maximisation. In the regulator's interpretation Enel's strategy reflected an aim of imposing some form of control over its competitors. ${ }^{68}$

The competition authority specifically regarded selective increase of the market price in the zone where Enel's market share in generation was largest as potentially abusive. The idea was that, by increasing the price 
in that zone, Enel's competitors that (a) did not own generation capacity in that market zone, and (b) had taken fixed price commitments in the retail market, would suffer a reduction in profits as a consequence of the increase in the congestion fee.

In our example the allegedly abusive behaviour consists of increasing the spot price in market zone B, which, other things being equal, would increase the congestion fee paid by a retailer that matched its sales to final consumers with production in zone A.

The case was dropped after the Italian competition authority accepted Enel's commitments to offer a certain number of forward contracts for delivery of electricity into the market zones where its market share was largest. In the context of our example, Enel committed to sell forward contracts for delivery at zone $\mathrm{B}$, which would also allow retailers with no generation capacity in that area to hedge against the volatility of the congestion fee.

\subsubsection{Abuse of Dominant Position in the System Operation Business}

The independence of the system operator is generally recognised as a necessary condition for the successful liberalisation of electricity markets. System operators control access to the transmission network in the short run by deciding the volume of transmission rights made available to market and running the allocating mechanism, and in the long run by planning network development. Discrimination in network access and delays in network upgrades can hinder competition in the wholesale as well the retail markets. Furthermore, the system operator is also the only buyer of ancillary services, a major source of income for some generating units.

In most markets some form of unbundling of system operator activities has been implemented in order to ensure the system operator's independence. The solutions implemented differ in three broad dimensions. The first is the scope of the system operator's responsibilities. At one extreme the system operator is responsible only for real-time system balancing. At the opposite extreme it controls a wide range of activities, including the transmission asset maintenance schedule, network development planning and generation capacity adequacy.

The second dimension relates to the degree of unbundling of system operations from the generation business. At one extreme the system operator is a fully ownership-separated company. The alternative approach is based on ring-fencing system operator activities from the integrated owner's generation activities. This is pursued through measures such as fully separated management teams, separate physical premises, Chinese 
walls, and independent audit boards or steering committees including representatives of both stakeholders and the regulator.

Finally, system operation arrangements differ in the degree of integration between the system operator and the transmission network operator. In some cases the system operator owns the transmission network; in others the transmission network is owned and operated by a different firm.

In Europe, several member states have selected ownership unbundling of (integrated) system and transmission operators. These are the UK, Italy, several northern European countries and Spain. ${ }^{69}$ The other countries have opted for functionally unbundled system operators. In the US, ownership and functionally unbundled system operators also co-exist.

Ensuring the system operator's independence is a crucial energy policy objective. However, in a recent case the organisation of system operations was shaped by competition policy. In 2008 the European Commission opened a case against E.ON AG, ${ }^{70}$ at that time a large generator as well as the owner of a portion of the German electricity grid and the system operator of the area covered by its network. The concern was that E.ON might have abused its dominant position on the market for secondary reserve demand in the E.ON network area by discriminating between secondary reserve suppliers, favouring their affiliate generators, and by preventing generators from other member states from exporting balancing energy into the E.ON balancing market.

The case was dropped after the Commission accepted E.ON's commitments to divest its $380 / 220 \mathrm{kV}$-line transmission network, the system operation of the E.ON control area and related activities.

\section{NOTES}

1. Specifically, Article 102 of the Treaty on the Functioning of the European Union.

2. Bundeswettbetwerbhorde website, 12 June 2012.

3. For each price level, the residual demand represents market demand net of the volumes supplied by the firm's competitors. It summarises the effects of competition on the demand faced by the firm.

4. The European Commission in Case COMP/M.5549 EDF/SEGEBEL stated: 'It appears from the market investigation that a significant interaction exists between OTC traded electricity products and electricity products traded on organised markets. Similarly, sufficient interaction exits between financial and physical products as the former use the latter as underlying products'. See also European Commission's decisions in Case COMP/M.5224 - EDF/BRITISH ENERGY and Case COMP/M.5911 TENNET/ ELIA/GASUNIE/APX-ENDEX.

5. The assumption that competitive conditions in the wholesale electricity market are similar across many hours is justified by the stability of the supply conditions. The dynamics of installed generation and transmission capacity unfold over timeframes in 
the order of years, sometimes decades. Furthermore, as discussed in Chapter 2, generators' dynamic constraints make production and offer decisions in consecutive hours interdependent.

6. This assumes that congestion between the two zones is managed through locational pricing. For the discussion of competitive constraints in cases where transmission constraints are managed through re-dispatch, see Chapter 4.

7. See, for example, in Motta, M., 2004. Competition Policy: Theory and Practice, Cambridge: Cambridge University Press.

8. Commission Notice on the definition of the relevant market for the purposes of Community competition law (published in the Official Journal: OJ C 372, on 9 December 1997).

9. With the possible exception of very long-term multi-year contracts.

10. See European Commission's decisions in Case COMP/M.4180 - Gaz de France/ Suez; Case COMP/M.5224 - EDF/BRITISH ENERGY; Case COMP/M.5549 EDF/ SEGEBEL; and Case COMP/M.5911 TENNET/ELIA/GASUNIE/APX-ENDEX.

11. In Case COMP/M.3868 DONG/Elsam/Energi E2, for example, the Commission assessed that balancing energy and ancillary services are not easily substitutable by other electricity supplies. However, more recently, in Case COMP/M.5224 EDF/ BRITISH ENERGY, the Commission found that the British balancing market is not separate from the forward markets.

12. In US jargon, those generators apply for 'market-based rate authority'. See AEP Power Marketing, Inc. et al., 107 FERC 61,018 (2004).

13. Ibid., p. 43.

14. Nine periods are obtained by aggregating the off-peak, shoulder and peak hours in winter, summer and spring/autumn. The tenth period includes summer super-peak hours.

15. The European Commission has made no explicit assessment regarding separation of the markets depending on the time of delivery. In Case COMP/M.5467 RWE/ESSENT the European Commission stated: 'Within the market for generation and wholesale supply, the Dutch Competition Authority (the NMa) distinguishes between peak hours and off-peak hours. In addition, they also consider the possibility of a further distinction between peak and super-peak hours. However the response to the current market investigation in this regard was inconclusive. The definition of the relevant product market can therefore be left open, as this does not change the final assessment'.

16. Moselle, B., Newbery, D. and Harris, D., 2006. Factors Affecting Geographic Market Definition and Merger Control for the Dutch Electricity Sector, The Brattle Group Limited. Report undertaken for the Dutch Competition Authority (NMa).

17. 'Persistent differences in average peak prices and average off-peak prices indicate that peak and off-peak power may be separate products. If they were not, then presumably consumers would substitute peak and off-peak power until the prices of the two products came closer to one another' (ibid., p. 15).

18. The European Commission's market investigations in the context of merger control found that the geographical markets are normally national, but that they may sometimes be smaller or larger. Relevant elements considered in the Commission's analysis include market design, the existence of congestion and the existence of price correlations and price differentials across locations.

In Case COMP/M.3268 Sykdraft/Graninge, the Commission investigated the frequency and distribution of the different price areas in the Nordic electricity market. In Case COMP/M.3868 DONG/Elsam/Energi E2, the Commission ruled out a Nordicwide market definition, based on the assessment that for a very substantial fraction of the hours producers in West Denmark do not suffer any competitive constraints from producers in the rest of the Nordic region.

19. O'Donoghue, R. and Padilla, A.J., 2006. The Law and Economics of Article 82 EC, Oxford: Hart.

20. The HHI index ranges from 0 to 10,000 . 
21. In the Cournot model all suppliers simultaneously select the volume offered on the market.

22. Borenstein, S., Bushnell, J. and Knittel, C., 1999. 'Market Power in Electricity Markets: Beyond Concentration Measures', Energy Journal, 20(4), 65-88.

23. Fabra, N., de Frutos, M.-A. and von der Fehr, N-H., 2008. 'Investment Incentives and Auction Design in Electricity Markets', CEPR Discussion Papers, London.

24. An example can be found in Green, R. and Newbery, D.M., 1992. 'Competition in the British Electricity Spot Market', Journal of Political Economy, 100(5), 929-53.

25. Wolak, F., 2000. 'An Empirical Analysis of the Impact of Hedge Contracts on Bidding Behaviour in a Competitive Electricity Market', International Economic Journal, 14(2), 1-40; Wolak, F., 2003. 'Measuring Unilateral Market Power in Wholesale Electricity Markets: The California Market, 1998-2000', American Economic Review, 93(2), 425-30; Baselice, R., 2007. 'Italian Power Exchange and Unilateral Market Power in Italian Wholesale Electricity Market', paper presented at the 9th IAEE European Energy Conference, Florence, Italy, 10-13 June.

26. Below the value of lost load (see Chapter 2, Section 2.2.1).

27. Newbery, D.M., Green, R., Neuhoff, K. and Twomey, P., 2004. A Review of the Monitoring of Market Power, ETSO Report, November.

28. In a joint market investigation the Italian energy and competition authorities developed an index reflecting the possibility and the incentives for generators to exercise market power. The index is based on a comparison of the outcome for the generator of two strategies: selling pivotal capacity at the maximum possible price (for example, the price ceiling of $€ 500 / \mathrm{MWh}$ implemented on the Italian power exchange), or selling all its production at the estimated system marginal cost ('Fact-finding investigation into the state of liberalisation in the electricity sector', 2005, AGCM and AEEG).

29. If the applicant fails one or both tests, it can rebut the presumption of market power by offering additional evidence.

30. See Section 5.4.3.

31. As reported by Newbery et al., 2004 (see n. 27, above), p. 28. Sheffrin, A., 2002. 'Predicting Market Power Using the Residual Supply Index', paper presented at the FERC Market Monitoring Workshop, Washington, DC, 3-4 December.

32. Italian competition authority (AGCM) jointly with the Italian energy regulator (AEEG), 2005. Fact-finding Investigation into the State of Liberalisation in the Electricity Sector (IC22).

33. Congestion management in the Italian market is carried out by allocating the market transmission rights between market zones. As a consequence the electricity market-clearing prices may be different in different zones. A macro zone is an aggregate of neighbouring market zones in which the market-clearing price is often identical. AGCM carried out the pivotality assessment by macro zones for reasons of simplicity.

34. Borenstein, S., Bushnel, J. and Wolak, F., 2002. 'Measuring Market Inefficiencies in California's Restructured Wholesale Electricity Market', American Economic Review, 92(5), 1376-405; Joskow, P. and Kahn, E., 2002. 'A Quantitative Analysis of Pricing Behaviour in California's Wholesale Electricity Market During Summer 2000', Energy Journal, 23(4), 1-35; Mansur, E., 2001. 'Pricing Behavior in the Initial Summer of the Restructured PJM Wholesale Electricity Market', POWER Working Paper 083; Sector Inquiry under Art 17 Regulation 1/2003 on the gas and electricity markets (final report), 2007, $\operatorname{COM(2006)} 851$ final; Weigt, H. and Von Hirschhausen, C., 2007. 'Price Formation and Market Power in the German Electricity Wholesale Market Is Big Really Beautiful?', Electricity Markets Working Papers WP-EM-16, Dresden University of Technology.

35. More details on the issue of assessing generating costs are given in Harvey, S. and Hogan, W., 2001. Identifying the Exercise of Market Power in California, LECG, LLC, Cambridge, MA; Harvey, S. and Hogan, W., 2002. Market Power and Market Simulations, LECG, LLC, Cambridge, MA; Smeers, Y., 2005. 'How Well Can One 
Measure Market Power in Restructured Electricity Systems?', CORE Discussion Paper No. 2005/50; Rajaraman, R. and Alvarado, F., 2003. 'Disproving Market Power', PSERC Working Paper; and Mansur, E., 2008. 'Measuring Welfare in Restructured Electricity Markets', Review of Economics and Statistics, 90(2), 369-86.

36. In this section we draw extensively from Federico, G. and López, A., 2009. 'Divesting Power', IESE Business School Working Paper No. 812.

37. Examples of mergers or joint ventures in the electricity sector where divestments or virtual power plants (VPPs) have been required by the competition authorities include Gas Natural/Union Fenosa (2009), EDF/British Energy (2008), Gas Natural/Endesa (2006), GDF/Suez (2006), Nuon/Reliant (2003), ESB/Statoil (2002) and EDF/EnBW (2000). Alleged abuse of dominance cases where divestments of generation capacity or VPPs have been implemented as a remedy include proceedings involving E.ON (2008), RWE (2008) and Enel (2006). Divestments of power plants have also been used by regulators to mitigate the market power of incumbent generators in the UK and Italy in the 1990s, while in Spain and Portugal regulatory contracts and more recently VPPs have been employed to make the electricity market more competitive.

38. Federico and López 2009 (see n. 36, above).

39. This result provides a foundation for the widely held view that ownership of pricesetting units grants greater market power than ownership of base-load capacity.

40. Some relevant references are: Allaz, B. and Vila, J.-L., 1993. 'Cournot Competition, Forward Markets and Efficiency', Journal of Economic Theory, 59, 1-16; Newbery, D., 1998. 'Competition, Contracts and Entry in the Electricity Spot Markets', RAND Journal of Economics, 29, 726-49; Green, R., 1999. 'The Electricity Contract Market in England and Wales', Journal of Industrial Economics, 47, 107-24; and Bushnell, J., 2007. 'Oligopoly Equilibria in Electricity Contract Markets', Journal of Regulatory Economics, 32, 225-45.

41. In 2000 the physical rights to output of existing generators built under the previous regulatory environment were auctioned off as Power Purchase Arrangements (PPAs). PPAs are auction biddable contracts that cover the embedded costs of existing generation. The PPAs were auctioned to interested parties. The holder of a PPA is entitled to sell the output of the generating plants directly to consumers in exchange for paying the owner the actual cost of generating power over the remaining life of the facility or until 2020, whichever comes first.

42. These are a series of options, each with strike price equal to the variable cost of the generating unit that it is meant to hedge.

43. A condition that we analysed in Chapter 2, Section 2.2.1.

44. See Chapter 3.

45. For a detailed analysis of the market-power mitigation mechanisms implemented in the US, see Reitzes, J., Pfeifenberger, J., Fox-Penner, P., Basheda, G., Garcia, J., Newell, S. and Schumacher, A., 2007. 'Review of PJM's Market Power Mitigation Practices in Comparison to Other Organized Electricity Markets', Brattle Group, Cambridge, MA, September.

46. PJM Interconnection is a US Regional Transmission Organisation (RTO) that coordinates the movement of wholesale electricity in all or parts of 13 states and the District of Columbia.

47. By assessing whether any three non-affiliated suppliers together are pivotal, PJM mitigates the unilateral and also the coordinated exercise of market power.

48. Recall that in the US standard market design transmission constraints are enforced within the market-clearing algorithm. Therefore market-clearing dispatch in the baseline scenario meets all the network constraints but the one for which the three pivotal supplier test is being carried out.

49. This might lead the generators to offer prices lower than their variable costs.

50. Tribunal de Defensa de la Competencia: Resolución Expte. 552/02, Empresas eléctricas; Resolución Expte. 602/05, Viesgo Generación; Resolución Expte. 601/05, Iberdrola Castellón and Resolución Expte. 624/07, Iberdrola. 
51. For example in: Resolución Expte. 602/05, Viesgo Generación the Spanish competition authority states: 'ENEL VIESGO GENERACIÓN, S.L., es responsable de una infracción al artículo 6 de la $L D C$, consistente en abusar de su posición de dominio en el mercado de energía eléctrica en una situación de restricciones técnicas de las zonas Centro-Sur y Sur, los . . ofertando al mercado diario a precios superiores a sus Costes Variables Revelados, con el objeto de no casar en el mercado diario y sabiendo que sería llamada a restricciones técnicas, y pagada a su precio de oferta al diario, porque su energía era necesaria para satisfacer la demanda de la zona, al ser la única disponible en la misma'.

52. Ofgem, 2009, Addressing Market Power Concerns in the Electricity Wholesale Sector Initial Policy Proposals.

53. UK Energy Act 2010, Chapter 27, Part 3.

54. For Spain, see Comisión Nacional de Energia: Propuesta de retribución regulada para el mecanismo de resolución de restricciones técnicas, 15 April 2010, available at: http://www.cne.es/cne/doc/publicaciones/cne27_10.pdf. For Germany, see Bundesnetzagentur Redispatch-Workshop bei der Bundesnetzagentur am 07.12.2011, Vergütung für Redispatchmaßnahmen, available at: http://www.bundesnetzagentur.de.

55. See Elspot market overview, available at: http://www.nordpoolspot.com/Market-data1/ Maps/Elspot-Market-Overview/Elspot-Prices/.

56. It is easy to verify that the total generation cost is lower when the interconnection capacity is set at $400 \mathrm{MW}$ and re-dispatch takes place.

57. The different distribution effect is caused by the different allocation of production among generators at the various locations and at the different market-clearing prices. The latter effect does not show in our simple example with flat supply functions.

58. Case/COMP 39.351, Commission Opens Proceedings Against Swedish Electricity Transmission System Operator Concerning Limiting Interconnector Capacity for Electricity Exports, MEMO/09/191, 23 April 2009.

59. Case/COMP 39.351, Commission Market Tests Commitments Proposed by Svenska Kraftnät Concerning Swedish Electricity Transmission Market, IP/09/1425, 6 October 2009.

60. Case/COMP 39.351, Commitments under Article 9 of Council Regulation No 1/2003, Svenska Kraftnät, 1 September 2009.

61. In some cases, retail prices are indexed to the value of a basket of fuels that is meant to reflect the dynamics of the (incremental) cost of generation in the market. However, this kind of indexation has no impact on the issues discussed in this section.

62. Congestion management via locational prices implies that consumers pay different prices for electricity solely because of their location. However, nationwide price uniformity for essential goods such as electricity has traditionally been a social policy objective in Italy. The asymmetric pricing system was introduced to overcome political opposition to locational prices. As long as demand is price inelastic, the absence of locational signals on the demand side does not produce inefficiencies, because charging loads the uniform price or the nodal price does not change withdrawals. Inefficiency caused by lack of locational signals on the demand side is more likely to result in a longer-term horizon, to the extent that (especially) large customers' location decisions are affected.

63. Further detail on the congestion management system implemented in the Italian market can be found in the Vademecum of the Italian Power Exchange, available at: http:// www.mercatoelettrico.org/En/MenuBiblioteca/Documenti/20091112VademecumofI pex.pdf.

64. Obtained as $(6,000 / 9,000) * 90 \mathrm{MW}$.

65. Obtained as $(3,000 / 9,000) * 90 \mathrm{MW}$.

66. And that cannot enter a forward contract for delivery in zone B.

67. Autorità Garante per la Concorrenza e il Mercato: Opening of Proceedings No. 14174 - A366, Comportamenti restrittivi sulla borsa elettrica, 6 April 2005.

68. In the Opening of Proceedings (ibid.) the Italian Competition Authority states: ' $L a$ strategia di Enel, nella sua globalità, appare riconducibile ad un'unica finalità, che è 
quella di esercitare il proprio potere di mercato dettando le strategie di prezzo all'ingrosso dell'energia elettrica e determinando, oltre le proprie, anche le condizioni concorrenziali dei suoi concorrenti, in modo tale da evitare confronti competitivi anche in quei mercati geografici rilevanti ove ciò avrebbe potuto, almeno potenzialmente e limitatamente, avvenire (il Nord e la Sardegna)'.

69. See Stern, J., 2011. 'System operators: lessons from US and EU energy industry experience and implications for the England and Wales water industry', CCRP Working Paper No. 18.

70. Case COMP/39.389 - German Electricity Balancing Market, 26 November 2011. 